California State University, Monterey Bay

Digital Commons@ @ CSUMB

SNS Master's Theses

School of Natural Sciences

Spring 2011

\title{
Marine Debris in Central California: Quantifying Type and Abundance of Beach Litter in Monterey Bay, CA
}

Carolyn Rosevelt

California State University, Monterey Bay

Follow this and additional works at: https://digitalcommons.csumb.edu/sns_theses

\section{Recommended Citation}

Rosevelt, Carolyn, "Marine Debris in Central California: Quantifying Type and Abundance of Beach Litter in Monterey Bay, CA" (2011). SNS Master's Theses. 18.

https://digitalcommons.csumb.edu/sns_theses/18

This Master's Thesis (Open Access) is brought to you for free and open access by the School of Natural Sciences at Digital Commons @ CSUMB. It has been accepted for inclusion in SNS Master's Theses by an authorized administrator of Digital Commons @ CSUMB. For more information, please contact digitalcommons@csumb.edu. 


\title{
MARINE DEBRIS IN CENTRAL CALIFORNIA: QUANTIFYING TYPE AND ABUNDANCE OF BEACH LITTER IN MONTEREY BAY, CA
}

\author{
A Thesis \\ Presented to the \\ Faculty of the \\ Division of Science and Environmental Policy \\ California State University Monterey Bay \\ In Partial Fulfillment \\ of the Requirements for the Degree \\ Master of Science \\ in
}

Coastal and Watershed Science and Policy

by

Carolyn Rosevelt

Spring 2011 


\section{CALIFORNIA STATE UNIVERSITY MONTEREY BAY}

The Undersigned Faculty Committee Approves the

Thesis of Carolyn Rosevelt:

\section{MARINE DEBRIS IN CENTRAL CALIFORNIA: QUANTIFYING TYPE AND ABUNDANCE OF BEACH LITTER IN MONTEREY BAY, CA}

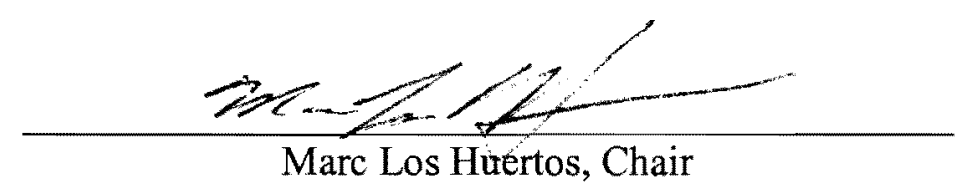

Division of Science and Environmental Policy, CSUMB

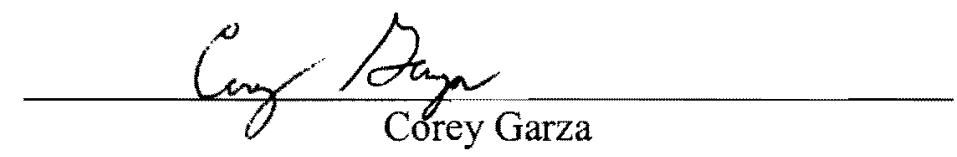

Division of Science and Environmental Policy, CSUMB

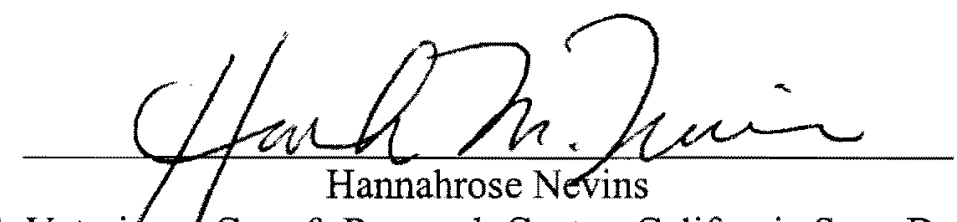

Marine Wildlife Veterinary Care \& Research Center, California State Department of Fish and Game, Santa Cruz, $\mathrm{Ca}$

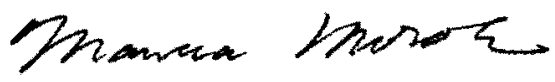

Marsha Moroh, Dean

College of Science, Media, Arts, and Technology

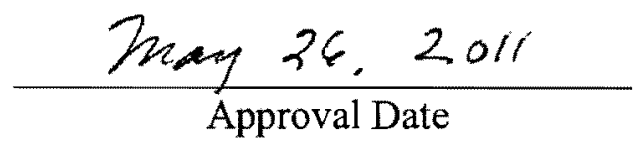


Copyright (C) 2011

by

Carolyn Rosevelt

All Rights Reserved 


\section{DEDICATION}

In memory of my Grandfather, Charles Schroeder. You were always supportive of my dreams. Thank you, Grandpa. 
Up on the watershed, standing in the fork in the road... $\sim$ E. Saliers 


\begin{abstract}
Marine Debris in Central California: Quantifying Type and

Abundance of Beach Litter in Monterey Bay, $\mathrm{Ca}$

by

Carolyn Rosevelt

Master of Science in Coastal and Watershed Science and Policy

California State University Monterey Bay, 2011
\end{abstract}

The Monterey Bay on the central coast of California lies within a protected marine sanctuary where recreation, tourism, and marine species coexist. Marine debris washing ashore poses a human health risk as well as contributes to economic losses and ecological harm. Central California's coastal managers require reliable scientific information on debris abundance, distribution, and type to help ameliorate this threat. To help address potentially harmful beach debris, I created a survey method that allowed for trained volunteers to quantify the types and abundance of beach litter. This method was put into effect at twelve beaches within the Monterey Bay in California. Utilizing trained volunteers increased efficiency and allowed the simultaneous sampling of twelve beaches monthly over one year. We conducted surveys at low tide from July 2009 through June 2010 . Beaches in the survey were: Santa Cruz Main, Seabright, Live Oak, Capitola, New Brighton, Seacliff, Manresa, Sunset, Zmudowski, Marina, Seaside, and Del Monte. Volunteers randomly placed quadrats to facilitate data collection along two parallel $50 \mathrm{~m}$ transects at each survey site. We found litter on all beaches surveyed; a total of 5966 individual pieces of litter were collected. Styrofoam made up $41 \%$ of the total amount of litter, making it the most numerically abundant item. Unexpected items included plastic pellets ( $9 \%$ of total plastics) and fertilizer capsules ( $1 \%$ of total litter). I analyzed spatial and temporal relationships between litter abundance using mixed effects modeling, and best fit was ascertained using Akaike's Information Criterion (AIC). The results of this study demonstrated that beach location, while influential, had less of an effect on litter abundance than month. The temporal and spatial variance in litter type and abundance suggest a relationship to physical and environmental factors, such as proximity to agricultural fields and surface current movement within the bay. The results of this study can be directly applicable to developing monitoring programs for beach debris and could be adopted by coastal cities to monitor their own environmental and political successes in beach litter abatement. In addition, this study has strengthened relationships with agencies, municipalities, educators and community organizations, as these relationships are essential for decision-making, scientific monitoring, and community outreach. 


\section{TABLE OF CONTENTS}

PAGE

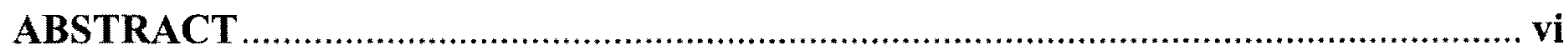

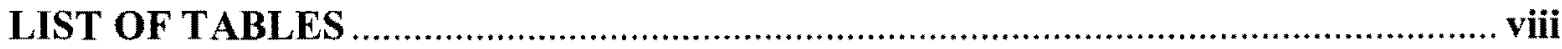

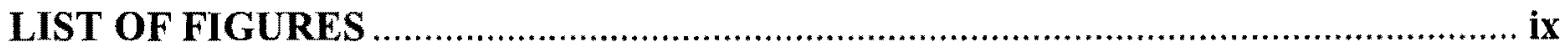

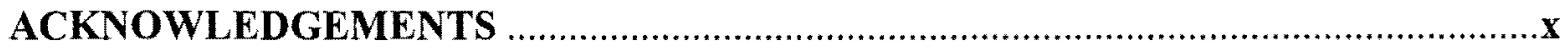

MARINE DEBRIS IN CENTRAL CALIFORNIA: QUANTIFYING TYPE AND

ABUNDANCE OF BEACH LITTER IN MONTEREY BAY, CA ................................

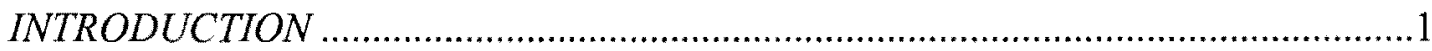

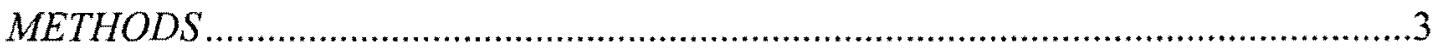

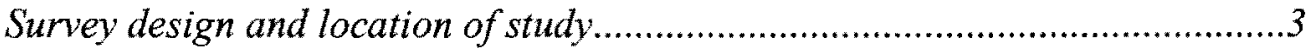

Beach survey methods ............................................................................4

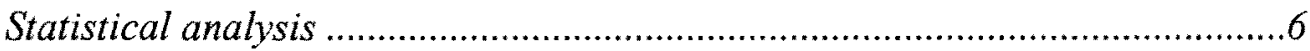

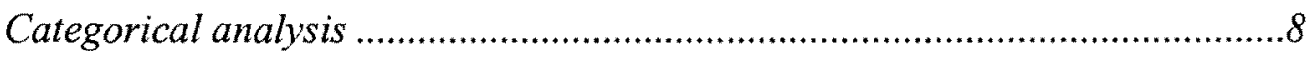

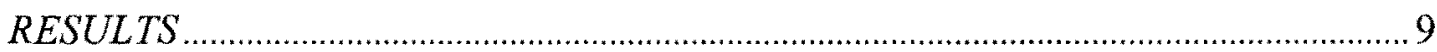

Temporal and spatial abundance of beach litter .......................................9

Modeling mixed effects: independence and variance structures ...................11

Quantities and types of debris............................................................

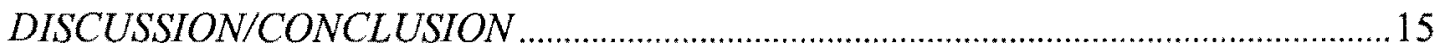

Low versus high accessibility beaches: exploring new hypotheses ...............16

The fate of plastic pellets: ingestion and contaminants ..............................17

Implications of beach litter studies on the Central Coast of California..........18

Future regional goals and recommendations ...........................................19

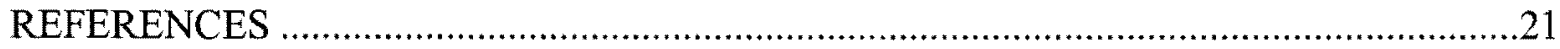

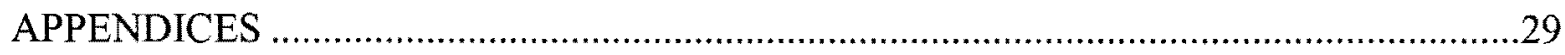

A BEACH-BASED SURVEYS: A LITERATURE REVIEW

B DIAGNOSTIC STATISTICAL ANALYSIS

C TABLES AND GRAPHS OF CATEGORICAL DATA

D R CODE 


\section{LIST OF TABLES}

PAGE

Table 1: AIC model comparison results: linear regression ...............................................11

Table 2: AIC model comparison results: gls and lme models ........................................12

Table 3: Percentage of general litter by type ..................................................................13

Table 4: Percentage of plastic litter by type....................................................................13

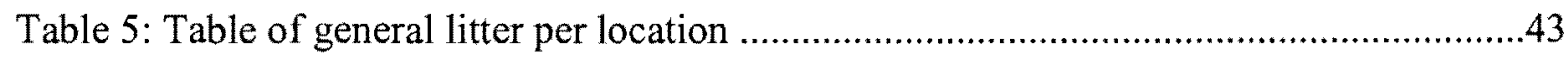

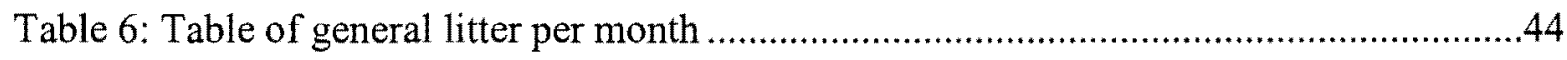

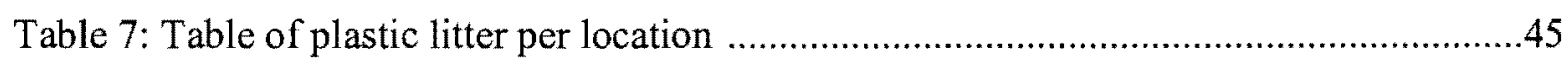

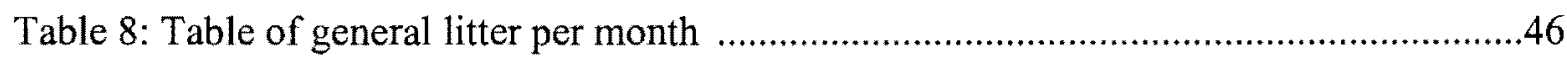




\section{LIST OF FIGURES}

PAGE

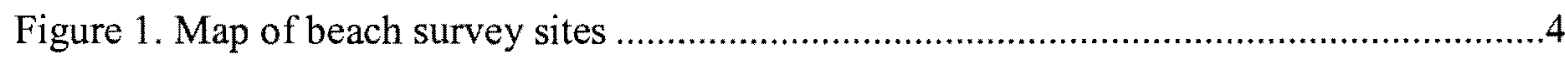

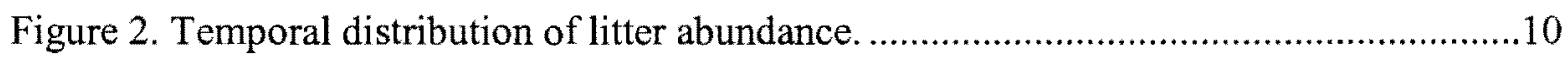

Figure 3. Spatial distribution and abundance of litter types. .................................................14

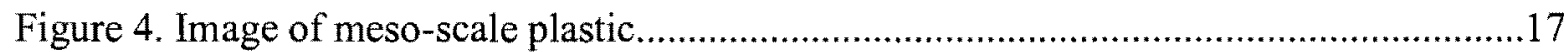

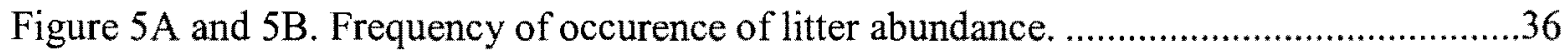

Figure 6A and 6B. Boxplot of litter abundance temporal and spatial distribution..................37

Figure 7. Regression diagnostics evaluating model assumptions on Model $_{1}$

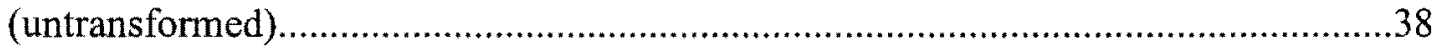

Figure 8. Regression diagnostics evaluating model assumptions on Model $_{1}(\log$ -

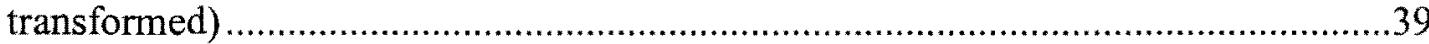

Figure 9. Auto-correlation plot (ACF) of GLS Model

Figure 10. X-Y plot of temporal litter abundance per location..............................................4

Figure 11. X-Y plot of spatial litter abundance per month ..................................................42

Figure 12. Spatial abundance of general litter categories .....................................................47

Figure 13. Temporal abundance of general litter categories....................................................48

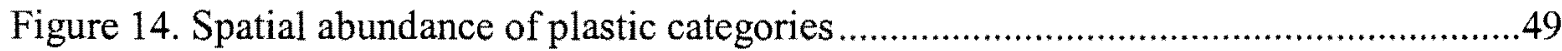

Figure 15. Temporal abundance of plastic categories ..........................................................50 


\section{ACKNOWLEDGEMENTS}

Thank you especially to all the volunteers for your commitment, enthusiasm, and hard work and to Hannah Nevins for her vision, encouragement, and support. Thanks to Mitchell Vernon an intern from the Undergraduate Research Opportunity Center (UROC) for his tireless attention to detail and dedication while assisting data collection. Erin Stanfield, Joel Rosenfeld, Joni Cady, and Miles Daniels offered useful insights, and my graduate committee provided extensive and constructive comments, facilitating my final draft. I also thank the Monterey Bay National Marine Sanctuary staff for their time and support. In addition, my committee members, Dr. Marc Los Huertos and Dr. Corey Garza offered generous guidance, patience, and helpful feedback throughout. Lastly, I thank my wife, Susie, for her wisdom, curiosity, and risk taking. 


\section{MARINE DEBRIS IN CENTRAL CALIFORNIA: QUANTIFYING TYPE AND ABUNDANCE OF BEACH LITTER IN MONTEREY BAY, CA}

\section{Introduction}

The term "marine debris" as defined by the National Oceanic and Atmospheric Administration (NOAA) and the U.S. Coast Guard is "any persistent solid material that is manufactured or processed and directly or indirectly, intentionally or unintentionally, disposed of or abandoned into the marine environment or the Great Lakes" (CFR 2009). Marine debris or litter washing ashore poses a threat to human health, regional economies, and marine species survivorship (Ryan et al. 1988; Ballance et al. 2000; Derraik 2002; Pendleton and Kildow 2006; Sheavely and Resister 2007; Teuten et al. 2009). For instance, accidental ingestion of plastic litter by wildlife can have devastating impacts on ecologically sensitive species such as sea turtles, marine mammals, seabirds, fish, and invertebrates (Hjelmeland et al. 1988; McCauly and Bjorndal 1999; Pierrepont et al. 2005; Ryan 2008; Graham and Thompson 2009). Accidental ingestion of plastic has been found in 82 out of 144 species of seabirds leading to both illness and fatalities due to starvation (Ryan 2008).

Potentially harmful marine litter is often measured by land-based surveys along shorelines (Frost and Cullen 1997; Cunningham and Wilson 2003; Storrier et al. 2007). Beach surveys can identify the distribution and variation in litter quantity and type, through aggregate spatial and temporal beach monitoring (Rees and Pond 1995; Kusui and Noda 2003; Edyvane et al. 2004; Oigmann-Pszczol and Creed 2007). Better understanding this variability will assist state and local regulators and managers in implementing appropriate levels of litter abatement to ameliorate any threats to the bay, vegetation, and sea life. I developed a citizen monitoring method to quantify beach litter and evaluated the temporal and spatial variability of litter occurring in Monterey Bay in California.

Beach litter surveys have been conducted around the globe for the purposes of better understanding the types and distribution of marine debris (Golick and Gertner 1992, Uneputty and Evan 1997, Velander and Mocogni 1998, Kusui and Noda 2003).

While beach surveys have been used in Southern California (Moore et al. 2001), 
scientific efforts to quantify litter on beaches on the Central Coast is lacking. Few studies have documented the presence and ecological hazards of marine debris in the Monterey Bay (Baltz and Morejohn 1976; Moore et al. 2009; Watters et al. 2010). Previous studies have documented the gut content of seabirds and found evidence of plastic ingestion (Baltz and Morejohn 1976). From 2001 to 2005 researchers investigated the occurrence of seabird entanglement in derelict fishing gear (Moore et al. 2009). Watters et al. (2010) more recently conducted boat-based research to map and categorize the abundance and distribution of underwater benthic debris within the Monterey Bay, yet continuous monitoring and litter quantification is lacking. Other studies elsewhere have relied upon beach surveys to assess the scale of the distribution of both land-based and oceanic marine debris (Ribic 1992; Moore et al. 2001).

Not only are beach surveys used for quantifying marine debris, they are also deemed an efficient method for collecting accurate and statistically comparable data with trained volunteers and inexpensive equipment (Rees and Pond 1995). Belt or strip transect survey methods are often used to collect litter from the surface of the beach (Frost and Cullen 1997; Cunningham and Wilson 2003; Storrier et al. 2007). Solely using the transect design typically results in identifying items larger than $2 \mathrm{~cm}$ (macrodebris) (Ribic 1992; Ryan et al. 2009). Yet few beach surveys sample buried litter and items smaller than $2 \mathrm{~cm}$ (meso-debris), which may also require the use of quadrats and sieves to sample accumulated litter (Williams and Tudor 2001; Kusui and Noda 2003; McDermid and McMullen 2004). Storrier and McGlashan (2006) and Ryan et al. (2009) suggest inaccuracies in results of beach surveys when using transects alone, since this method frequently fails to capture meso-scale debris $(<2 \mathrm{~cm})$. This can result in an underestimation of beach litter abundance.

My main research goal was to support coastal managers and stakeholders in addressing the issue of marine debris within the Monterey Bay. The objectives of this study were to 1) assess the presence of meso-scale litter; 2) identify temporal and spatial patterns in litter abundance; 3) identify types of litter and examine patterns, and 4) involve citizens in science-based research through ongoing beach surveys. To address these objectives I focused on three research questions: 
(i) Do month and or beach location have an influence on litter abundance?

(ii) Does litter abundance differ between sites characterized as having low or high accessibility?

(iii) Is there a relationship between litter type and month or location?

\section{Methods}

\section{Survey design and location of study}

The survey design was a repeated measures approach that enabled the identification of temporal and spatial patterns in litter abundance (items $\mathrm{m}^{-2}$ ) (Vonesh and Chinchilli 1997; Gotelli and Ellison 2004; Zurr et al. 2009). To test the role of beach location on the abundance of litter, I chose a variety of beach sites. This study included 12 survey sites from north to south in Monterey Bay: Main, Seabright, Live Oak, Capitola, New Brighton, Seacliff, Manresa, Sunset, Zmudowski, Marina, Seaside, and Del Monte beaches (Figure 1). In this study the sampling unit was the beach location. To improve the spatial extent of beach area covered by volunteer effort, I deployed random sampling across two parallel $50 \mathrm{~m}$ transects within each sampling unit (Moore et al. 2001; Cunningham and Wilson 2003). I summed the total litter abundance and categorical count of litter collected along the two $50 \mathrm{~m}$ transects within each beach. The use of $4 \mathrm{~m}^{2}$ quadrats facilitated litter collection and categorical identification. Each survey was comprised of randomly allocated quadrats across each transect, and quadrat positions differed each month depending on location of the wrack line (freshest high tide mark). Using quadrats also facilitated surface and subsurface sampling ( $\sim 2 \mathrm{~cm}$ in depth) of beach substrate. I quantified the abundance of beach litter as items $\mathrm{m}^{-2}$.

To further assess temporal and spatial patterns in litter abundance, we choose several beach locations across the Monterey Bay. Beach location was based on several criteria: access, consistency, and proximity to municipalities. Beaches such as Main, Seabright, and Del Monte were chosen because of previous beach clean up events there; they could be a useful indicator of litter persistence. Because accessibility is another independent variable that may affect litter abundance, I chose public access sites with high and low accessibility (Figure 1). I classified low accessibility sites as beaches adjacent to areas with population density less than 1000 people $\mathrm{km}^{-2}$ (based on city 
population density information). Beach locations greater than $5 \mathrm{~km}$ from the nearest city were also classified as low accessibility (US Census 2000).

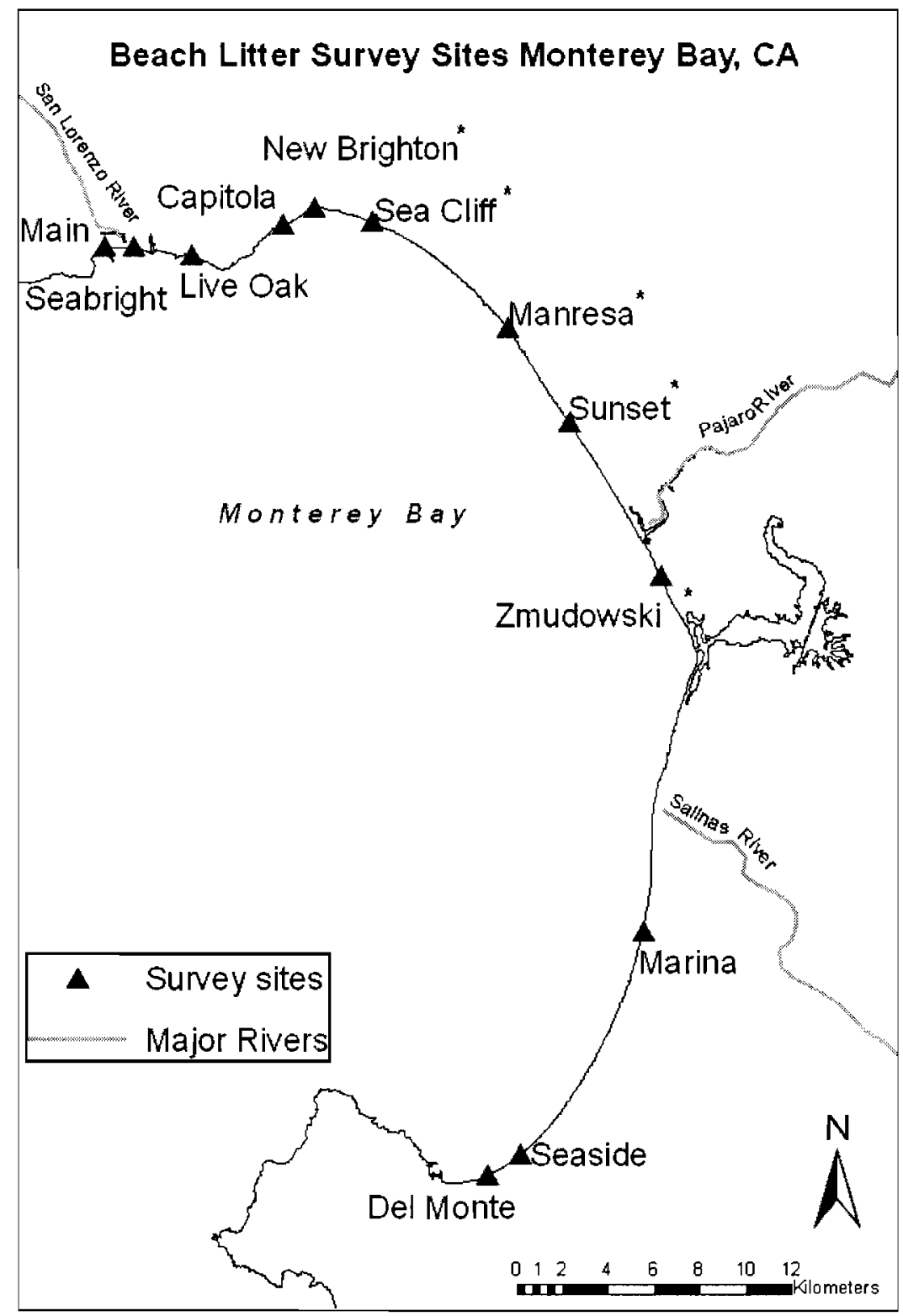

Figure 1. Map of beach survey sites with in the Monterey Bay, CA. Locations with an asterisk indicate a low accessibility beach location.

Beach survey methods

A survey method was developed to investigate the relationship between environmental variables and temporal and spatial variation in litter abundance and composition. I assessed the temporal and spatial influences on litter abundance by conducting monthly surveys at twelve beaches simultaneously throughout the Monterey 
Bay (Figure 1). Surveys occurred semi-monthly from July through September 2009 and monthly from September 2009 through June 2010. The average was taken of beaches that were surveyed twice a month. Trained volunteers collected monthly samples at the same site over the course of one year.

Prior to beginning their work volunteers participated in 2 hours of mandatory training. This involved a 30 minute presentation covering the scientific method, harmful impacts of marine debris, survey equipment, and a review of the beach survey protocol. Immediately following the presentation, volunteers actively participated in a demonstration of the protocol at a nearby beach. Following Ribic's (1992) recommendations regarding volunteer effort, six teams comprised of at least two volunteers each, conducted surveys, and each team surveyed two beaches per event. This simultaneous multi-team approach increased efficiency and accuracy in measurements otherwise thwarted by the daily variation in litter deposition.

We carried out surveys at low tide, providing optimal beach surface area for sampling within the survey design. The first of two transects was placed within the strandline since previous studies have shown this region as a deposition zone for plastics (Velander and Mocogni 1998, 1999; Corcoran et al. 2008; Ryan et al. 2009). Following the protocols of Cunningham and Wilson (2003), a second transect was positioned $5 \mathrm{~m}$ above the first transect line, A pin flag demarcated the start of each transect. Five $4 \mathrm{~m}^{2}$ quadrats were randomly placed along both transect lines for the purposes of sampling meso-scale $(>2 \mathrm{~mm}$ to $<2 \mathrm{~cm}$ ) and macro-scale $(>2 \mathrm{~cm})$ beach litter (Velander and Mocogni 1999; McDermid and McMullen 2004). Each month new random numbers were generated within the $\mathrm{R}$ statistical package, to designate the number of volunteer paces taken along each transect line for quadrat placement (one through five). Volunteers demarcated each sequential sampling plot by reusing a $4 \mathrm{~m}^{2} \mathrm{PVC}$ quadrat as they progressed along the line. Upon scanning the surface of each quadrat for litter, volunteers used their fingertips to conduct subsurface sampling by raking the sandy surface in a light back and forth motion, feeling, and looking for buried litter. Digging was strongly discouraged and approximate raking depth was $2 \mathrm{~cm}$. Volunteers collected 
all anthropogenic debris from each quadrat, tallied the data sheets, and placed litter into labeled resealable bags.

\section{Statistical analysis: Mixed effects modeling, exploring litter abundance}

To investigate the influence of time and location on litter abundance, I applied a series of statistical models to the data. These models were used to estimate the relational strength between the independent variables (month and beach location) and dependent variable (litter abundance). A log transformation of the litter abundance data was necessary to conduct statistical analyses that assume a normal distribution (Ribic et al. 2010). Continuing with the assumption of normally distributed data, I performed a linear regression on all models (Appendix D). Mixed effects modeling addressed the lack of independence, correlation, and variance between the continuous dependent variable (litter abundance) and its categorical covariates (beach location and month) (Pinheiro and Bates 2000 ). Using a mixed effects model approach within a repeated measures design incorporated fixed and random effects (Pinheiro and Bates 2000; Zuur et al. 2009). Random effects are typically associated with the sampling unit that represents values drawn from a larger population, in this case beach location (Pinheiro and Bates 2000). By defining beach location as a random effect, it allows for extrapolation to be made about litter abundance from the sampling unit to the greater population (litter on all beaches in the Monterey Bay) (Venables and Ripley 2002). In contrast, fixed effects are typically associated with the entire population and not the sampling unit (Lindsey 1997; Pinheiro and Bates 2000). Here I define month as the fixed effect because the entire population in this study refers to all beach litter in the Monterey Bay measured by the temporal variable month.

I used a weighted linear regression known as a generalized least squares (GLS) model to address the heterogeneity in the repeated measure design (Zuur et al. 2009). The GLS model is used when dealing with heterogeneity (variance per stratum) in data and can allow for additional components such as variance structures to be fit to the model (Zuur et al. 2009). Violation of independence due to the repeated measures design was ascertained by statistical analysis using the auto-correlation function (ACF) (Zuur et al. 
2009). This allowed the violation of independence to be addressed by fitting an AutoRegressive Moving Average (ARMA) correlation structure to the model with the best fit (Zuur et al. 2009). Additionally, linear mixed effects (LME) models incorporate both the random and fixed effects (Zuur et al. 2009). The LME models allow for the incorporation of the variance structures in the GLS model to be incorporated into a new model that also has a random effect (Zuur et al. 2009). The statistical software package $R$ was used to estimate descriptive statistics and to perform diagnostics on all models $(R$ Development Core Team 2008). Akaike's Information Criterion (AIC) was used to determine the best of the three models that describes the relationship between beach location, month, and litter abundance. The first model $\left(\mathrm{Model}_{1}\right)$ included both spatial and temporal covariates, and the other two included a combination of one or the other covariate $\left(\mathrm{Model}_{2}, \mathrm{Model}_{3}\right)$.

$M_{1}:_{\text {Abundance }_{i j}}=\alpha+\beta_{0}+\beta_{1}$ Location $_{i j}+\beta_{2}$ Month $_{i j}+\varepsilon_{i j}$

$M_{2}:$ Abundance $_{i j}=\alpha+\beta_{0}+\beta_{1}$ Month $_{i j}+\varepsilon_{i j}$

$M_{3}:_{\text {Abundance }_{i j}}=\alpha+\beta_{0}+\beta_{1}$ Location $_{i j}+\varepsilon_{i j}$

where Abundance is litter abundance (items $/ \mathrm{m}^{2}$ ), $\alpha$ is the population intercept (when $\mathrm{X}=0$, $\mathrm{Y}=0$ ), $\beta_{0}$ is the population slope (when $\mathrm{X}$ increases by one unit, what is the expected increase in Y), $\beta_{l}$ is the coefficient of location, $\beta_{2}$ is the coefficient of month, Month is the categorical name of the month during the study, Location is the categorical beach location name, $\varepsilon$ is error term with a Gaussian distribution, $i$ is the different beach locations, and $j$ is the different months when surveying occurred. In this study, AIC was used to identify and explore likely relationships between litter abundance over space and time, which are driven by anthropogenic and environmental factors. While physical drivers were not measured and analyzed in this study, environmental factors affecting amounts of marine debris are hypothesized later in the discussion.

Analysis of low vs. high accessibility beaches 
This study assumed that more highly accessible beaches would accumulate more litter. I qualified each survey site's proximity to densely populated towns and cities as described in the methods to identify if litter abundance differs between low and high accessibility beaches. Two different types of beaches, lower accessibility and higher accessibility beaches, were quantified by their respective litter abundance measurements. I used Wilcoxon tests to statistically assess the relationship between litter abundance at low and high accessibility beach locations. The following hypothesis was tested:

$\mathrm{H}_{0 \mathrm{a}}$ : Litter abundance is the same between beaches that have low and high accessibility. $\mathrm{H}_{1 \mathrm{a}}$ : Litter abundance differs between beaches that have low and high accessibility. (where sub $\mathrm{a}=$ anthropogenic hypothesis)

\section{Categorical analysis}

To assess the relationship between litter type and month and location, the total count of each litter category was organized into two-way contingency tables (Appendix C). The classification of litter items fell into 13 general types: fragmented plastic, glass, paper/treated wood, plastic products, Styrofoam, rubber, metal, cigarette butts, fabric, fertilizer capsules, fishing gear, food wrappers, and other (items with ambiguous identity, e.g., paint chips). Styrofoam was considered a separate category during documentation and analysis, since it was often treated as a stand alone item in previous studies (Moore et al. 2001; Kusui and Noda 2003; Storrier et al. 2007). The subcategory of plastic materials was cumulatively and separately summed and analyzed (Appendix $C$ ). The statistical test used was the McNemar test, a nonparametric version of a Chi-square test used in repeated measure designs (Agresti 1996). McNemar tests marginal homogeneity between the predictor and response variables and is a standard test used in the analysis of contingency tables (Agresti 1996, Sun and Yang 2008). I tested the following hypothesis to analyze the spatial association of litter categories:

$\mathrm{H}_{0 \mathrm{c}}$ : Litter category is not associated with beach location. $\mathrm{H}_{2 \mathrm{c}}$ : Litter category is associated with beach location. 
(where sub $\mathrm{c}=$ categorical spatial hypothesis)

An association of the temporal distribution of litter categories was tested by the following hypothesis:

$\mathrm{H}_{0 \mathrm{t}}$ : Litter category is not associated with month.

$\mathrm{H}_{31}$ : Litter category is associated with month.

(where sub $t=$ categorical temporal hypothesis)

Quality control and litter enumeration methods

Litter was analyzed in the laboratory. I assessed the presence and abundance of meso-scale litter by measuring all fragmented plastic and I divided and identified them as three class sizes: micro-debris $(<2 \mathrm{~mm})$, macro debris $(>2.0 \mathrm{~cm}$ diameter), and mesodebris $(2 \mathrm{~mm}-2.0 \mathrm{~cm})$ (Cheshire et al. 2009). Analysis included performing quality control (confirming quantity and category) by the comparison of all items collected against that recorded by field observers. I used a microscope to differentiate between biological and synthetic composition when necessary. Early in the study, volunteers mistook bleached sea grass for plastic strips, and using a microscope confirmed that this biological material had a plant cell structure.

\section{Results}

Temporal and spatial abundance of beach litter

The model that included both temporal and spatial covariates $\left(\operatorname{Model}_{1}\right)$ was the best fit given the abundance data (Table 1). Between the two predictor variables, month ( $\left(\mathrm{Model}_{2}\right)$ described the data more closely based on AIC model comparison (Table 1). Statistical support for Model $_{1}$ is likely related to the temporal model $\left(\mathrm{Model}_{2}\right)$ having a stronger affect on the variation in litter abundance between survey months (Appendix B). In addition, no significant difference was found between litter abundance on low versus high accessibility beach locations $(p=0.55)$. This finding supported by AIC model comparison, confirms that the spatial model $\left(\mathrm{Model}_{3}\right)$ explains a minimal amount of 
variation in litter abundance (Table 1). Beaches in the center and most northern and southern survey sites had greater average litter abundance over time and thus were identified as "hot spots" including Main, Seabright, Sunset, Zmudowski, Seaside and Del Monte beaches (Figure 2). Unexpectedly, during the winter season, survey sites located along the middle of the Monterey Bay (mainly comprised of low accessibility beaches) demonstrated substantial increases in average litter abundance (Figure 2).

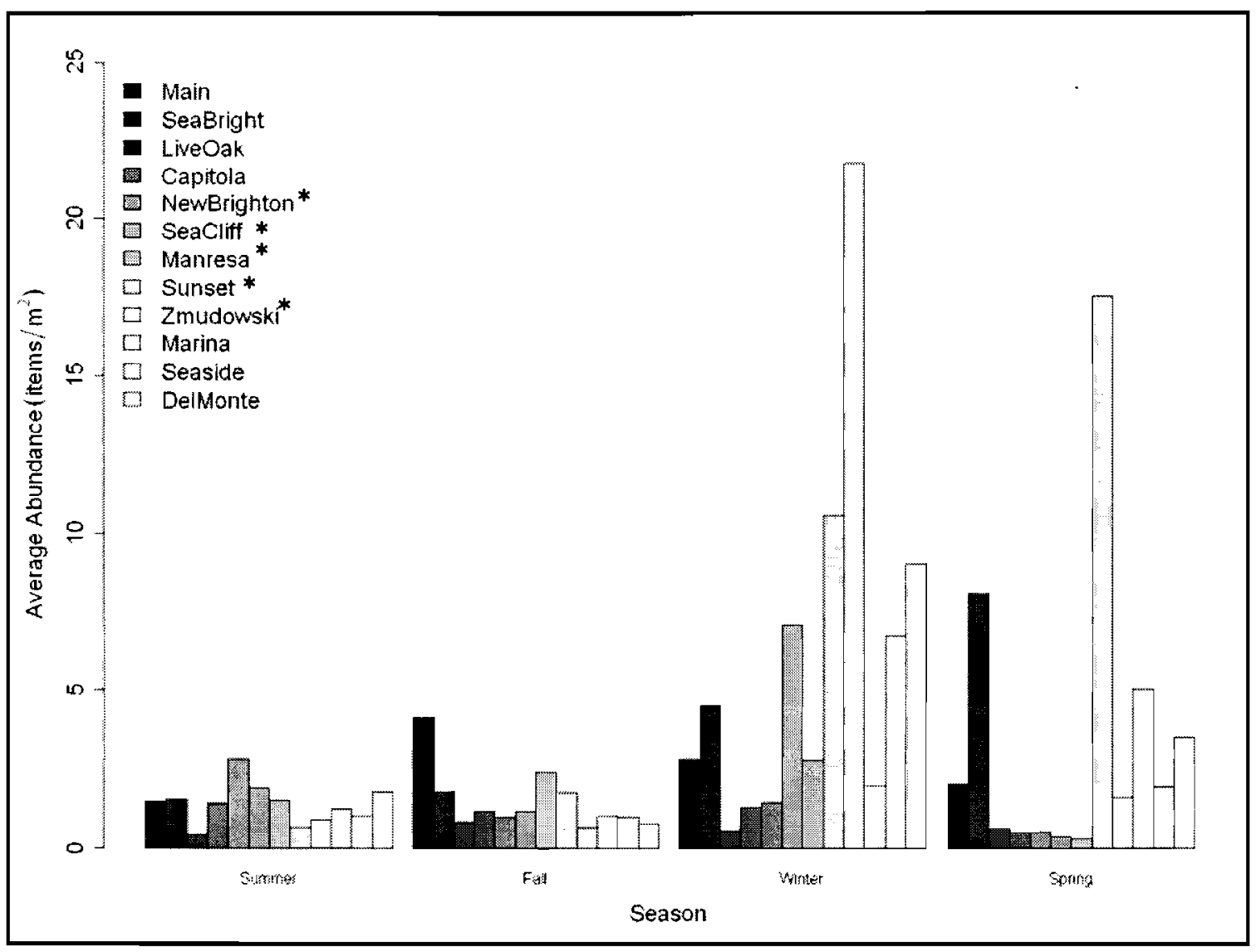

Figure 2. Distribution of average seasonal litter abundance per beach location from north to south from July 2009 to June 2010. An asterisk demarcates low accessibility beaches. 
Table 1. AIC table summarizing model comparison results for simple linear regression models. Model $_{1}$ includes both covariates, while Model $_{2}$ describes the temporal effect on litter abundance. Model ${ }_{3}$ describes the spatial effect on litter abundance. Nomenclature follows Burnham and Anderson (1996): degrees of freedom (df), AIC corrected for small sample size $\left(\mathrm{AIC}_{\mathrm{c}}\right)$, differences from the best model (delAIC), and AIC weights $\left(\mathrm{AIC}_{\mathrm{w}}\right)$.

\begin{tabular}{lccccc}
\multicolumn{1}{c}{ Model } & df & AIC & AICc & delAIC & AICw \\
\hline \hline Model $_{\text {nul }}$ & 2 & 479.88 & 467.88 & 60.60 & 0.00 \\
Model $_{1}$ & 24 & 459.46 & 407.28 & 0.00 & 1.00 \\
Model $_{2}$ & 13 & 462.24 & 431.90 & 24.62 & 0.00 \\
Model $_{3}$ & 13 & 484.06 & 453.73 & 46.45 & 0.00
\end{tabular}

Modeling mixed effects: independence and variance structures

The GLS model ( Model $_{4}$ ) using a variance structure for month was the best fit given the data (Table 2). This suggests that the amount of variance in litter abundance between months had an influential effect on litter abundance over spatial location. The random effect, beach location, was analyzed in $\mathrm{Model}_{5}$ using a LME model (Table 2). However, this random intercept model does not include the variance structure (as with the GLS model) and only includes beach location as a random effect. Without the temporal variance structure, Model $_{5}$ explained the least amount of variance in litter abundance (Table 2). Model $_{6}$ also was fitted with a LME model and included both beach location as a random effect and the variance structure for month (Table 2 and Appendix D). AIC results from Model $_{6}$ and Model $_{5}$ suggest that beach location does not influence litter abundance as strongly as month (Table 2). Litter abundance measurements were autocorrelated over time, violating the assumption of independence between survey events (Appendix B). Fitting ARMA to Model $_{4}$ resulted in identifying that litter abundance was temporally correlated by a time step of two. Litter abundance at Seabright beach in September, for example, was auto-correlated with litter abundance in July and August. 
Table 2. AIC table summarizing model comparison results of using GLS and $L M E$ models. See Table 1 for heading definitions.

\begin{tabular}{lccccc}
\multicolumn{1}{c}{ Model } & df & AIC & AICc & delAIC & AICw \\
\hline \hline Model $_{\text {glsnul }}$ & 2 & 482.45 & 470.45 & 82.72 & 0.00 \\
Model $_{4}$ & 35 & 461.85 & 387.73 & 0.00 & 1.00 \\
Model $_{5}$ & 14 & 465.02 & 432.71 & 44.98 & 0.00 \\
Model $_{6}$ & 25 & 452.76 & 398.60 & 10.87 & 0.00
\end{tabular}

Quantities, distribution, and types of debris

The largest percentage of litter by total number was Styrofoam (41\%) (Table 3). Styrofoam occurred at $100 \%$ of all survey sites (Appendix C). Marginal heterogeneity was found between the different types of litter across time and location and this suggests litter type is significantly different between both months and beach location $(p<0.01)$. This finding corroborates results from the AIC model comparisons, where month and beach location affect quantities of litter. The second largest percentage of litter by total number was fragmented plastics. Fragmented plastics also occurred at $100 \%$ of all survey sites (Appendix C) and made up 68\% of all plastic litter subcategories (Table 4). The mean length measurement of fragmented plastics was approximately $1 \mathrm{~cm}$, well within the meso-scale classification. It should be noted that only one piece out of all measured fragmented plastic was considered to be in the micro-plastic size range $(<0.2$ $\mathrm{cm})$.

Tables 3 and 4 highlight and delineate two groupings of litter items: general types of litter (Table 3 ) and the subcategory of exclusively plastic items (Table 4). Fertilizer capsules, a previously undocumented item, occurred at $25 \%$ of all survey sites. The largest quantities were found during winter months at Zmudowski Beach but were also found as far north as Seabright Beach (Table 3, Figure 3). Plastic pellets occurred at 67\% of all survey sites (Appendix C) and were the second largest subcategory of plastic material, comprising $9 \%$ of all plastics found (Table 4). Many pellets appeared to have been discolored (aged) from photo degradation. While pellets were found in high concentration at Sunset Beach in March, they occurred minimally elsewhere and were completely absent from four northern beaches throughout the year (Figure 3). 
Table 3. Percent of total number of general items from July 2009 to June 2010, including most common spatial and temporal occurrence ( $n=12$ months).

\begin{tabular}{llll}
\hline Items & Percent & Beach & Season \\
\hline \hline & & & \\
Styrofoam & $41 \%$ & Zmudowski* & Winter \\
Plastics & $36 \%$ & Sunset* & Winter \\
Cigarette Butts & $6 \%$ & Main & Summer \\
Paper/Wood & $5 \%$ & Main & Summer \\
Food wrappers & $5 \%$ & Main & Summer \\
Fertilizer capsules & $1 \%$ & Zmudowski* & Winter
\end{tabular}

Table 4. Percent of total number of exclusively plastic items from July 2009 to June 2010 , including most common spatial and temporal occurrence ( $n=12$ months).

\begin{tabular}{llll}
\hline Items & Percent & Beach & Season \\
\hline \hline & & & \\
Fragmented plastic & $68 \%$ & Sunset* & Winter \\
Plastic pellets & $9 \%$ & Sunset* & Winter \\
Straw/wrappers & $4 \%$ & Main & Summer \\
Bottle Caps & $3 \%$ & Sea Cliff & Summer \\
Plastic bags & $1 \%$ & Marina & Summer \\
Firecrakers & $1 \%$ & Sunset* & Summer
\end{tabular}




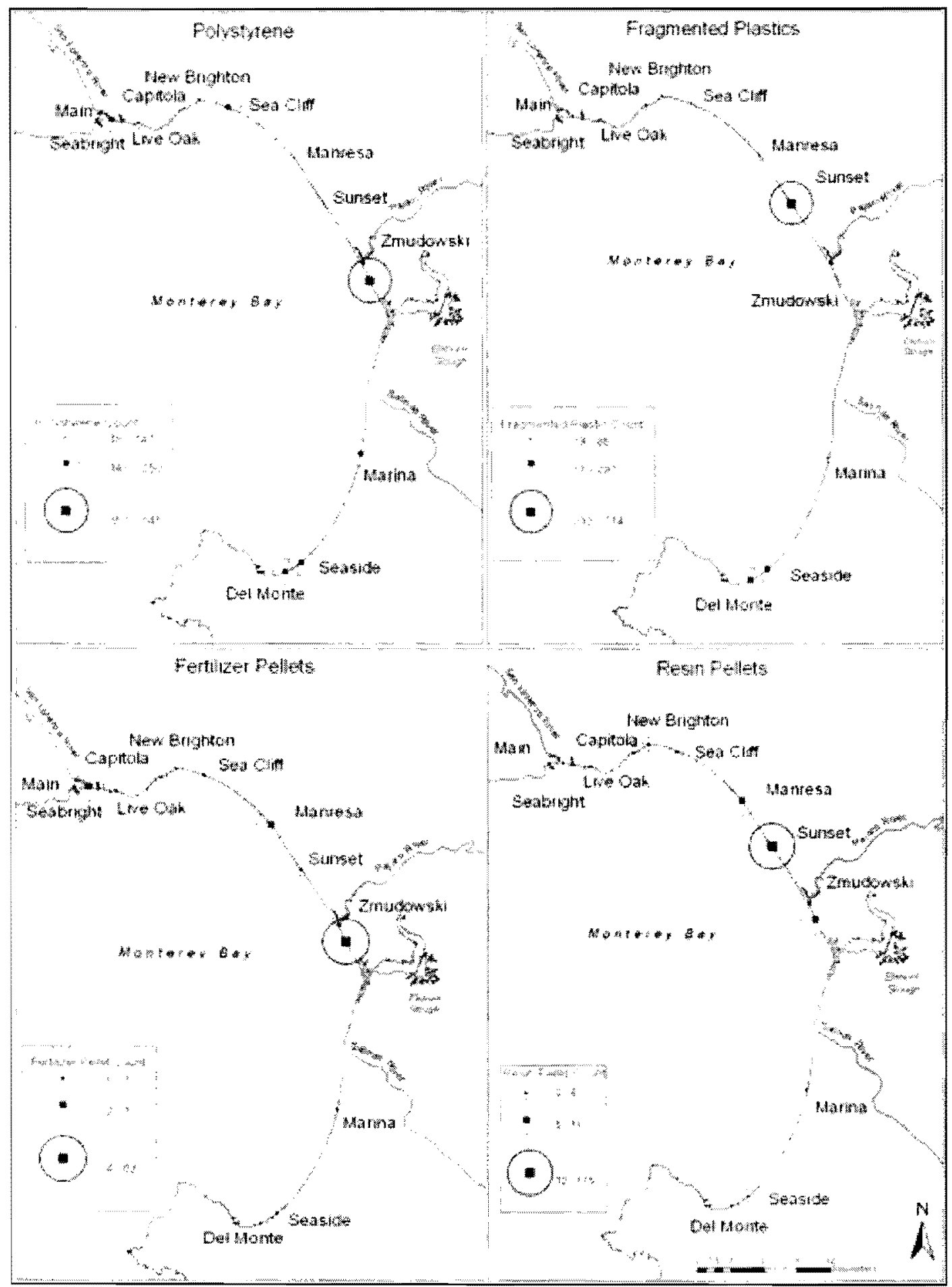

Figure 3. Distribution of total amounts of Styrofoam, fragmented plastics, fertilizer capsules, and plastic pellets per survey site over the entire study period $(n=12$ months). The scale of quantities is independent between panels. 


\section{Discussion}

Regardless of origin or source of litter, survey equipment and techniques used in this study facilitated the documentation of unexpected meso-scale litter types. It was unexpected to find high concentrations of fragmented plastics and Styrofoam at lower accessibility beaches, Meso-scale litter is present however, affected by season, and a major component of all marine debris along Monterey Bay beaches. Seasonal changes in surface currents and wind direction during the study presumably led to changes in abundance and composition of litter within Monterey Bay. Ocean currents, for example, are dynamic systems affecting the dispersal of floating marine debris (Wong 1974). Researchers have found that surface current velocity and direction in the Monterey Bay change seasonally, and circulation can even change in a matter of days or weeks, weakening the ability to predict directional or temporal patterns (Paduan and Rosenfeld 1996; Paduan and Cook 1997). Spring's northwest winds have an effect on surface currents (Nelson 1977; Rosenfeld et al. 1994) and may transport plastic pellets and fragmented plastics toward hot-spot beaches, as demonstrated by Sunset Beach in the month of March. Other physical drivers, such as winter storms associated with El Niño and seasonal increases in river run-off, are plausible causes for the temporal variation found in this study.

In contrast to our knowledge of ocean currents, there is less understanding of the role rivers play in transporting debris to the coastline (Moore et al. 2005; Araujo and Costa 2007). Araujo and Costa (2007) have associated increased litter abundance with beach proximity to rivers. Four beaches in this current study are in close proximity to a river or large creek mouth: Main Beach, Seabright, Capitola, and Zmudowski. During the winter months, substantially more fertilizer capsules ( $2 \mathrm{~mm}$ in size) were recorded at $\mathrm{Zmudowski}$ beach, which is adjacent to the Pajaro River. These casings are the remains of time-release fertilizer applications on inland plots (Moe et al. 1967). It is reasonable to believe the casings may have been introduced to Zmudowski beach in winter months via the Pajaro River mouth, which is supplied and connected by a network of agricultural ditches, creeks, and ponds (Los Huertos et al. 2001). In contrast, Seabright and Capitola beaches had fewer casings and lower agricultural land use. It is important to note that the 
San Lorenzo River (Main and Seabright) and Soquel Creek (Capitola) are not surrounded with substantial agricultural activity as are the Pajaro and

Salinas Rivers.

Low versus high accessibility: exploring new hypotheses

While beach visitor density (or accessibility) was not measured here, Rodrigues-

Santos et al. (2005) found that tourism is a leading cause of beach litter and that the quantity of litter depends on beach visitor density. We found no difference between litter abundance on lower and highly accessible beach locations in the current study. This finding is unexpected. It was thought that even low accessibility beaches in Monterey Bay may be visited more frequently than population proximity would predict. Existing litter removal efforts may be increasing in frequency in areas with the greatest population density (i.e., mechanical cleanings, community service, beach clean-ups, and independent citizen clean-up) which may also affect results.

Anecdotal evidence suggests the process of mechanical beach cleaning (occurring at high accessibility beaches) may increase the number but reduce the size of plastic items. We found evidence to this effect. On more than one occasion, surveyors found newly broken plastic fragments where recent mechanical cleanings had left large tire ruts in the sand. The number of fragmented plastic is further exacerbated because small pieces of plastic are long lasting and become perpetually buried and uncovered over time (Williams and Tudor 2001). Fragmented plastics found on low accessibility beaches could be unintentionally dug up from the subsurface of the beach by wave action (Kusui and Noda 2003), sand erosion (Patsch and Griggs 2006), dogs, and human activities. Many fragmented pieces of plastic showed evidence of extended time in the marine environment or surf zone, including photo-degradation (fading in color), abrasions, and fractures (Figure 4). A few plastic items included biological organisms affixed to the anthropogenic substrate. For example, a colony of bryozoans had settled on one bottle cap, demonstrating evidence of long oceanic exposure (Figure 4). Litter deposition through ocean currents and river run off during winter months, as well as concurrent substantial sand erosion may explain why low accessibility beaches such as Zmudowski and Sunset contained high counts of fragmented plastics and Styrofoam in winter. 


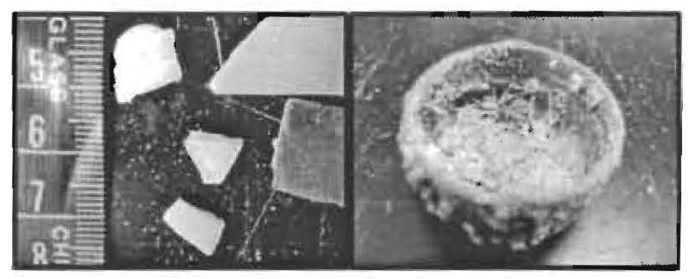

Figure 4. Examples of meso-scale plastic fragments and biota attached to a bottle cap.

The fate of plastic pellets: ingestion and contaminants

The intent of this study was to capture meso-scale debris $(2 \mathrm{~mm}$ to $2 \mathrm{~cm}$ ) that is often buried (Kusui and Noda 2003; Cochran 2009) and can pose a direct threat to wildlife in the Monterey Bay National Marine Sanctuary. Plastic pellets, for example, have been mistaken as food items by seabirds (Nevins et al. 2005; Ryan 2008). Once plastic is ingested it remains in the guts and stomachs of seabirds and may block or impair digestion (Fry et al. 1987). Procellariforms (Petrels and Shearwaters) are one family of seabird that is particularly susceptible to plastic (Ryan 1987). Effects of plastic ingestion include blockage of the intestine caused by a plastic bottle cap and ulceration of the gizzard (Pierce et al. 2004). The frequency of fragmented plastics found in this study may be of concern to wildlife biologists since many species of seabirds forage in the waters of the Monterey Bay (Baltz and Morejohn 1976, 1977).

The quantity of plastic pellets found in this study is comparable to the percentage of pellets found during beach surveys in Hawaii (McDermid and McMullen 2004). Kusui and Noda (2003) found that pellets were the second most abundance source of plastic litter. Plastic pellets have a great capacity to attract and transport persistent organic pollutants (POPs) such as dichloro-diphenyl-trichloroethane (DDT) and polychlorinated biphenyls (Mato et al. 2001). In addition to adverse effects on wildlife, DDT has been found in higher concentrations in the Monterey Bay Canyon than elsewhere on the Central Coast due to agricultural run-off (Hartwell 2008). The adsorption of POPs including DDT and pesticides onto resin pellets could be occurring at a local scale. Beach surveys in Southern California have identified significantly large quantities of resin pellets, and which may be sourced to accidental release into the environment at plastic manufacturing facilities, where beach deposition was accentuated 
by the close proximity to rivers and urban run-off (Moore et al. 2001). Furthermore, oceanographic currents may transport buoyant pellets from more populated southern regions of California into the Monterey Bay during the southerly reversal of the California Current (i.e. Davidson Current). Another potential source of these pellets may be from accidental spillage during marine transport, which could expedite pellets entering the Monterey Bay.

\section{Implications of beach litter studies on the Central Coast of California}

Litter that flows out of storm drains is a significant source of marine debris, with discarded plastics being a major constituent (Lippner et al 2001; Derraik 2002). Preventing litter from polluting the coastal environment is an ongoing and complex management issue. On the federal level, the Coastal Zone Act Reauthorization Amendments (CZARA) Section 6217 incorporates a management measure to reduce litter (EPA 1993). The goal of the management measure is to implement pollution prevention and education programs to reduce non-point source (NPS) pollutants caused by anthropogenic discharge into storm drains. The National Oceanic and Atmospheric Administration and the United States Environment Protection Agency (USEPA) are responsible for implementing CZARA (EPA 1993). Additionally, NOAA and the USEPA have established general management measures for each state to adopt and follow as they strive towards preventing polluted runoff (EPA 1993).

The California State Water Resources Control Board (including nine Regional Water Quality Control Boards) and the California Coastal Commission (CCC) are responsible for the protection of state waters. The Central Coast Regional Water Quality Control Board (CCRWQCB) regulates litter from construction and industrial sites but does not regulate municipal litter produced by storm water and urban run-off (Epp per comm.). A proposed statewide policy for preventing and controlling trash in state waters is currently in debate and is commonly referred to as the "trash policy" (SWRCB and CalEPA 2010). This policy would identify trash as a separate pollutant within pointsource and NPS parameters and establish methods to control trash pollution in waters of the state (SWRCB and CalEPA 2010). The proposed policy recognizes that plastics are 
one of the most abundant litter sources (SWRCB and CalEPA 2010). The proposed statewide legislation would call for inclusive regulatory actions including monitoring of "hot spots". Beach litter surveys are an ideal tool to monitor coastal areas with high litter accumulation or output (SWRCB and CalEPA 2010).

\section{Future regional goals and recommendations}

Based on the results of this study, I have identified an overarching recommendation to federal government management regarding increased understanding of marine debris sources and mitigation in the Monterey Bay area. I recommend that the MBNMS (a government agency) incorporate beach litter monitoring into their existing volunteer monitoring network. Incorporating survey methods for continuous monitoring would lead to ongoing identification of "hot spot" beaches, which may change over time. Continuous monitoring can also help target and ameliorate litter accumulation at hot spot beaches where state and municipal waste management can then provide more litter receptacles and educational signage. Another benefit of continuous monitoring would enable local Non-profits to focus their clean up efforts on specific seasons and beach locations. For instance, Save Our Shores in Santa Cruz County should focus beach cleanups on inner bay sites (Manresa and Sunset) during winter and beaches adjacent to populated areas in Santa Cruz and Capitola in summer months. The local chapter of Surfrider in Monterey County should focus beach clean-ups on inner bay sites such as Zmudowski and possibly Salinas River and Fort Ord Dunes State Beach during winter and beaches adjacent to Seaside and Monterey during summer.

Appropriate monitoring methods adoptable by the MBNMS may include the continuation of monthly sampling, surveying fewer beaches, expanding the area sampled by quadrats, deploying 2-4 volunteers per site, and the omission of collecting litter (alternatively, identifying litter type during survey). Augmenting additional monitoring programs within the MBNMS monitoring network may add additional strain and increase staff workload. Additional work may mean increasing and augmenting volunteer trainings, added cost of survey supplies and materials, and taking actions to secure extra funding. However, the suggestions in this paper may keep costs down and public 
participation up though the incorporation of service learning and community service programs in schools and universities. Furthermore, because monitoring provides a longterm set of data that allows managers to identify and mitigate trends in litter type and abundance, continuous monitoring can support legislative mandates such as the proposed "trash policy" discussed above.

I suggest designing studies to better isolate the sources of litter in order to further understand the spatial and temporal patterns of beach litter. This may mean comparing litter at urban outfalls and storm drains with beach survey data. Other suggestions include modeling watershed drainage routes that flow into the MBNMS, modeling near shore surface currents for proximal litter deposition, and comparing effects of beach erosion on litter abundance during wet and dry seasons.

This study began the process of scientific quantification of beach litter in the Monterey Bay region. It has led to new knowledge of the locations, quantities, and types of debris on California's Central Coast. This study demonstrates that Styrofoam, although banned in many cities, is currently the most common type of beach litter. Although Styrofoam take-out containers are banned at restaurants, Styrofoam cups, plates, and coolers continue to be purchased and brought to the beach despite this ban. The presence of Styrofoam emphasizes the need to continue to promote manufacturer responsibility as well as legislative efforts to decrease Styrofoam use in packaging materials (Reck 1990). Upholding the aesthetics of our beaches by controlling litter load into storm drains is achievable, yet coastal managers will need to identify the hot spots within the Monterey Bay region (SWRCB 2010, CALEPA 2010). The overarching result of this research was building relationships with agencies, municipalities, educators, and community organizations. These relationships are essential for decision making, scientific monitoring, and community outreach that will benefit our mutual goals of a clean and healthy marine environment.

\section{REFERENCES}

Agresti A. 1996. An Introduction to Categorical Data Analysis. New York: Wiley. 
Aliani S, Griffa A, Molcard A. 2003. Floating debris in the Ligurian Sea, North-Western Mediterranean. Marine Pollution Bulletin, 46: 1142-1149.

Araújo MC, Costa M. 2007. An analysis of the riverine contribution to the solid wastes contamination of an isolated beach at the Brazilian Northeast. Management of Environmental Quality: An International Journal, 18(1): 6-12.

Ballance A, Ryan PG, Turpie JK. 2000. How much is a clean beach worth? The impact of litter on beach users in the Cape Peninsula, South Africa. South African Journal of Science, 96:210-213.

Baltz DM, Morejohn GV. 1976. Evidence from seabirds of plastic particle pollution off central California. Western Birds, 7: 111-112.

Baltz DM, Morejohn GV.1977. Food habits and niche overlap of seabirds wintering on Monterey Bay, California. The Auk 94(3): 526-543

Barnes DKA, Milner P. 2005. Drifting plastic and its consequences for sessile organism dispersal in the Atlantic Ocean. Marine Biology, 146: 815-825.

Blakemore F, Williams A. 2008. British tourists' valuation of a Turkish beach using contingent valuation and travel cost methods. Joumal of Coastal Research, 24(6):1469-1480.

Boland RC, Donohue MJ. 2003. Marine debris accumulation in the nearshore marine habitat of the endangered Hawaiian monk seal, Monachus schauinslandi 19992001. Marine Pollution Bulletin, 46: 1385-1394.

Brink P, Lutchman I, Bassi S, Speck S, Sheavly S, Register K, Woolaway C. 2009. Guidelines on the Use of Market-based Instruments to Address the Problem of Marine Litter. Institute for European Environmental Policy (IEEP), Brussels, Belgium, and Sheavly Consultants, Virginia, USA. 60pp.

Burnham KP, Anderson DR. 2002. Model Selection and Multimodel Inference: A Practical Information-Theoretic Approach. 2nd Edition. New York. Springer

Carpenter EJ, Smith KL. 1972. Plastics on the Sargasso Sea Surface. Science, 175(4027): $1240-1241$.

Cheshire AC, Adler E, Barbière J, Cohen Y, Evans S, Jarayabhand S, Jeftic L, Jung RT, Kinsey S, Kusui ET, Lavine I, Manyara P, Oosterbaan L, Pereira MA, Sheavly S, Tkalin A, Varadarajan S, Wenneker B, Westphalen G. 2009. UNEP/IOC Guidelines on Survey and Monitoring of Marine Litter. UNEP Regional Seas Reports and Studies, No. 186; IOC Technical Series No. 83: xii +120 pp.

Cho BR, Park C. 2005. Robust design modeling and optimization with unbalanced data. Computers and Industrial Engineering, 48:173-180.

[NRC] National Research Council. 2008. Committee on the Effectiveness of International and National Measures to Prevent and Reduce Marine Debris and Its Impacts. Report in Brief, Tackling Marine Debris in the $21^{\text {st }}$ Century..

Code of Federal Regulations. 2009. 33 U.S.C. 1951-1958 (2006); 33 CFR 1.05-1; Department of Homeland Security Delegation No. 0170.1. [74 FR 45560, Sept. 3, 2009]

Corcoran PL, Beisinger MC, Grifi M. 2009. Plastics and beaches: a degrading relationship. Marine Pollution Bulletin, 58:80-84. 
Crain AD, Eriksen M, Iguchi T, Jobling S, Laufer H, LeBlanc GA, Guillette Jr LJ. 2007. An ecological assessment of bisphenol-A: evidence from comparative biology. Reproductive Toxicology, 24 (2007) 225-239.

Cunell AM. 1973. Plastic materials accumulating in Narraganasett Bay. Marine Pollution Bulletin, 4:187-188.

Cunningham DJ, Wilson SP. 2003. Marine debris on beaches of the greater Sydney region. Journal of Coastal Research, 19(2): 421-430.

Dalgaard P. 2008. Introductory Statistics with R, 2nd ed., Springer, New York.

Derraik JGB. 2002. The pollution of the marine environment by plastic debris: a review. Marine Pollution Bulletin, 44:842-852.

Dixon TR, Cooke AJ. 1977. Discarded containers on a Kent beach. Marine Pollution Bulletin, 8(5): 105-109.

Dixon TJ, Dixon TR. 1983. Maine litter distribution and composition in the North Sea. Marine Pollution Bulletin, 14(4): 145-148.

Dowd BM, Press D, Los Huertos M. 2008. Agricultural nonpoint source water pollution policy: the case of California's Central Coast. Agriculture, Ecosystems and Environment, 128 (2008): 151-161.

Earll RC, Williams AT, Simmons SL, Tudor DT. 2000. Aquatic litter, management and prevention-the role of measurement. Journal of Coastal Conservation, 6(1):67-78.

Edyvane KS, Dalgetty A, Hone PW, Higman JS, Wace NM. 2004. Long-term marine litter monitoring in the remote Great Australian Bight, South Australia. Marine Pollution Bulletin, 48: 1060-1075.

[EPA] Environmental Protection Agency. 1993. Guidance Specifying Management Measures for Sources of Nonpoint Pollution in Coastal Waters. EPA 840-B-92002 January, http://www.epa.gov/owow_keep/nps/czara.html [cited 2010 October 15]

Frost A, Cullen M. 1997. Marine debris on Northern New South Wales beaches (Australia): sources and the role of beach usage. Marine Pollution Bulletin, 34(5): 348-352.

Galgani F, Burgeot T, Bocquene G, Vincent F, Leaute JP, Labastie J, Forest A, Guichet R. 1995. Distribution and abundance of debris on the continental shelf of the Bay of Biscay and in Seine Bay. Marine Pollution Bulletin, 30(1): 58-62.

Goldstein T, Johnson SP, Phillips AV, Hanni KD, Fauquier DA, Gulland FMD. 1999. Human-related injuries observed in live stranded pinnipeds along the central California coast 1986-1998. Aquatic Mammals, 25(1): 43-51.

Golik A, Gertner Y . 1992. Litter on the Israeli coastline. Marine Environmental Research, 33(1): 1-15.

Golik A. 1997. Debris in the Mediterranean Sea: types, quantities, and behavior. In: Coe JM, Rogers DB (Eds.) Marine Debris: Sources, Impacts, and Solutions. Springer, New York, pp 7-14.

Gotelli NJ, Ellison AM. 2004. A Primer of Ecological Statistics. Sinauer Associates, Inc. Publishers Sunderland, Massachusetts U.S.A.

Graham ER, Thompson JT. 2009. Deposit and suspension-feeding sea cucumbers (Echinodermata) ingest plastic fragments. Joumal of Experimental Marine Biology and Ecology, 368: 22-29. 
Hartwell IS. 2008. Distribution of DDT and other persistent organic contaminants in Canyons and on the continental shelf off the central California coast, Marine Environmental Research 65(3): 199-217.

Hartwig E, Clemens T, Heckroth M. 2007. Plastic debris as nesting material in a Kittiwake-(Rissa tridactyla)-colony at the Jammerbugt, Northwest Denmark. Marine Pollution Bulletin, 54: 595-597.

Hetherington J et al. The Marine Debris Research, Prevention and Reduction Act: A policy Analysis. Columbia University 2005.

Hjelmeland K, Pedersen BH, Nilsen EM. 1988. Trypsin content in intestines of herring larvae, Clupea harengus, ingesting inert styrofoam spheres or live crustacean prey. Marine Biology, (Berl.) 98: 331-335.

Hofman RJ. 1990. Cetacean entanglement in fishing gear. Mammal Review 20(1): 53-64.

Pendleton L, Kildow J. 2006. The non-market value of beach recreation in California. Shore \& Beach, 74(2): 34-37.

Kubota M, Takayama K. 2005. Pleading for the use of biodegradable polymers in favor of marine environments and to avoid an asbestos-like problem for the future. Applied Microbiology and Biotechnology, 67: 469-476.

Kusui T, Noda M. 2003. International survey on the distribution of stranded and buried litter on beaches along the Sea of Japan. Marine Pollution Bulletin, 47: 175-179.

Laist DW. 1997. Impacts of marine debris: entanglement of marine life in marine debris including a comprehensive list of species with entanglement and ingestion records. In Marine Debris: Sources, Impacts, and Solutions, eds. J. M. Coe and D. B. Rogers, pp. 99-139. New York: Springer.

Laist DW, Liffmann M. 2000. Impacts of marine debris: research and management needs. Issue papers of the International Marine Debris Conference, Aug. 6-11, 2000. Honolulu, Hawaii, pp 16-29.

Lecke-Mitchell KM, Mullin K. 1997. Floating marine debris in the US Gulf of Mexico. Marine Pollution Bulletin, 34(9): 702-705.

Levesque JC. 2009. Characterization of the southern US black sea bass (Centropristis striata) pot commercial fishery and implication for western North Atlantic right whale (Eubalaena glacialis) management and policy. Marine Policy, 33: 40-48.

Lindsey JK. 1997. Applying Generalized Linear Models. New York: Spinger-Verlag.

Lippner G, Johnston J, Combs S, Walter K, Marx D. 2001. Results of California Department of Transportation Litter Management Pilot Study. Transportation Research Record: Journal of the Transportation Research Board 1743: 10-15.

Los Huertos M, Gentry E, Shennan C. 2001. Land use and stream nitrogen concentrations in agricultural watersheds along the Central Coast of California. The Scientific World Journal, 1: 615-622.

Maffini MV, Rubin BS, Sonnenscein C, Soto AM. 2006. Endocrine disruptors and reproductive health: The case of bisphenol-A. Molecular and Cellular Endocrinology, 254-255(2006): 179-186.

Maso M, Garces J, Pages F, Camp J. 2003. Drifting plastic debris as a potential vector for dispersing harmful algal blooms (HAB) species. Scientia Marina (Barcelona), 67(1): 107-111. 
Matsumura S, Nasu K. 1997. Distribution of floating debris in the North Pacific Ocean: Sighting Surveys 1986-1991. In: Coe JM, Rogers DB (Eds.) Marine Debris: Sources, Impacts, and Solutions. Springer, New York, pp 15-24.

McCauley SJ, Bjorndal KA. 1999. Conservation implications of dietary dilution from debris ingestion: sublethal effects in post-hatchling Loggerhead sea turtles. Conservation Biology, 13(4): 925-929.

McCoy FW. 1988. Floating megalitter in the Eastern Mediterranean. Marine Pollution Bulletin, 19(1): 25-28.

McDermid KJ, McMullen TL. 2004. Quantitative analysis of small-plastic debris on beaches in the Hawaiian archipelago. Marine Pollution Bulletin, 48: 790-794.

Meirelles A, Barros H. 2007. Plastic debris ingested by rough-toothed dolphin (Steno bredanensis), stranded alive in northeastern Brazil. Biotemas, 20(1): 127-131.

Moe PG, Mannering JV, Johnson CB. 1967. Loss of fertilizer nitrogen in surface runoff water. Soil Science, (104)6: 389-394.

Moore CJ, Moore SL, Leecaster MK, Weisberg SB. 2001. A comparison of plastic and plankton in the North Pacific Central Gyre. Marine Pollution Bulletin, 42(12): 1297-1300.

Moore CJ. 2008. Synthetic polymers in the marine environment: a rapidly increasing, long-term threat. Environmental Research, 108: 131-139.

Moore E, Lyday S, Roletto J, Litle K, Parrish JK, Nevins H, Harvey J, Mortenson J, Greig D, Piazza M, Hermance A, Lee D, Adams D, Allen S, Kell S. 2009. Entanglements of marine mammals and seabirds in central California and the north-west coast of the United States 2001-2005. Marine Pollution Bulletin, 58 (2009) 1045-1051.

Moore SL, Allen MJ. 2000. Distribution of anthropogenic and natural debris on the mainland shelf of the Southern California bight. Marine Pollution Bulletin, 40(1): 83-88.

Moore SL, Gregrio D, Carreon M, Weisberg SB, Leecaster MK. 2001. Composition and distribution of beach debris in Orange Country, California. Marine Pollution Bulletin, 42(3): 241-245.

Morishige C, Donohue MJ, Flint E, Swenson C, Woolaway C. 2007. Factors affecting marine debris deposition at French Frigate Shoals, Northwestern Hawaiian Islands Marine National Monument, 1990-2006. Marine Pollution Bulletin, 54: 11621169.

Nelson CS. 1977. Wind stress and wind stress curl over the California Current. NOAA Technical Report NMFS SSRF-714, U.S. Department of Commerce, NOAA/NMFS, pp. 89.

Nevins H, Hyrenbach D, Keiper C, Stock J, Hester M, Harvey J. 2005. Seabirds as indicators of plastic pollution in the North Pacific, In: Rivers to Sea Conference Proceedings, September 7-9, 2005.

Ogi H, Fukumoto Y. 2000. A sorting method for small plastic debris floating on the sea surface and stranded on sandy beaches. Bulletin of the Faculty of Fisheries, Hokkaido University 51: 71-93. 
Oigman-Pszczol SS, Creed JC. 2007. Quantification and classification of marine litter on beaches along Armacao dos Buzios, Rio de Janeiro, Brazil. Journal of Coastal Research, 23(2): 421-428.

Paduan JD, Cook MS. 1997. Mapping surface currents in Monterey Bay with CODARtype HF radar. Oceanography 10(2): 49-52.

Paduan JD, Rosenfeld LK. 1996. Remotely sensed surface currents in Monterey Bay from shore-based HF radar (Coastal Ocean Dynamics Application Radar). Journal of Geophysical Research 101(C9):20,669-20,686.

Patsch K, Griggs G. 2006. Littoral cells, sand budgets, and beaches: Understanding California's shoreline, Institute of Marine Sciences University of California, Santa Cruz, http://www.dbaw.ca.gov/csmw/PDF/LittoralDrift.pdf

Pichel WG, Churnside JH, Veenstra TS, Foley DG, Friedman KS, Brainard RE, Nicoll JB, Zheng Q, Clemente-Colón P. 2007. Marine debris collects within the North Pacific Subtropical Convergence Zone. Marine Pollution Bulletin, 54(8): 12071211.

Pierce KE, Harris RJ, Larned LS, Pokras MA. 2004. Obstruction and starvation associated with plastic ingestion in a Northern Gannet Morus bassanus and a Greater Shearwater Puffinus gravi. Marine Orinthology 32:187-189.

Pierrepont JF, Dubois B, Desormonts S, Santos MB, Robin JP. 2005. Stomach contents of English Channel cetaceans stranded on the coast of Normandy. Journal of the Marine Biological Association of the United Kingdom, 85: 1539-1546.

Pinheiro JC, Bates DM. 2004. Mixed Effects Models in S and S-Plus. New York: Springer.

Pruter AT. 1987. Sources, quantities and distribution of persistent plastics in the marine environment. Marine Pollution Bulletin, 18(6B): 305-310.

$\mathrm{R}$ Development Core Team. 2008. R: A language and environment for statistical computing. R Foundation for Statistical Computing, Vienna, Austria. ISBN 3900051-07-0, URL http:/www.R-project.org.

Reck SM. 1990. Expanding environmental consciousness of local government: Municipalities that have banned Styrofoam and the legal consequences. $11 \mathrm{U}$. Bridgeport L. Rev. 127 (1990-1991).

Rees G, Pond K. 1995. Marine Litter monitoring programmes - a review of methods with special references to national surveys. Marine Pollution Bulletin, 30(2): 103-108.

Ribic CA, Dixon TR, Vining I. 1992. Marine debris survey manual. US Department of Commerce. NOAA Technical Report NMFS 108. Washington, DC, GPO.

Ribic CA. 1998. Use of indicator items to monitor marine debris on a New Jersey Beach from 1991 to 1996. Marine Pollution Bulletin, 36(11): 887-891

Ribic CA, Sheavly SB, Rugg DJ, Erdmann ES. 2010. Trends and drivers of marine debris on the Atlantic coast of the United States 1997-2007. Marine Pollution Bulletin, 60: $1231-1242$.

Rodriguez-Santos I, Friedrich AC, Wallner-Kersanach M, Fillmann G. 2005. Influence of socio-economic characteristics of beach users on litter generation. Ocean and Coastal Management, 48: 742-752. 
Rosenfeld LK, Schwing FB, Garfield N, Tracy DE. 1994. Bifurcated flow from an upwelling center: a cold water source for Monterey Bay. Cont. Shelf.Res., 14:931-964.

Ryan PG, Connell AD, Gardner BD. 1988. Plastic ingestion and PCBs in seabirds: is there a relationship? Marine Pollution Bulletin, 19(4): 174-176.

Ryan PG. 2008. Seabirds indicate changes in the composition of plastic litter in the Atlantic and south-western Indian Oceans. Marine Pollution Bulletin, 56: 14061409.

Ryan PG, Moore CJ, van Franeker JA, Moloney CL. 2009. Monitoring the abundance of plastic debris in the marine environment. Philosophical Transactions of the Royal Society B, 364: 1999-2012.

Scott G. 1972. Plastics packaging and coastal pollution. International Journal of Environmental Science, 3: 35-36.

SWRCB and CALEPA 2010. Informational Document: Public Scoping Meeting for Proposed Statewide Policy for Trash Control in Waters of the State, September 2010.

Sheavly SB. 2007. National Marine Debris Monitoring Program: Final Program Report, Data Analysis and Summary. Prepared for U.S. Environmental Protection Agency by Ocean Conservancy, Grant Number X83053401-02. 76 pp.

Sheavly SB, Register KM. 2007. Marine debris and plastics: environmental concerns, sources, impacts and solutions. Journal of Polymers and the Environment, 15: 301-305.

Shiomota A, Kameda T. 2005. Distribution of manufactured floating marine debris in near-shore area around Japan. Marine Pollution Bulletin, 50: 1430-1432.

Smith KV, Zhang X, Palmquist RB. 1997. Marine debris, beach quality, and non-market values. Environmental and Resource Economics, 10: 223-247.

Stamper MA, Whitaker BR, Schofield TD. 2006. Case study: morbidity in a pygmy sperm whale Kogia breviceps due to ocean-bourne plastic. Marine Mammal Science, 22(3): 719-722.

Storrier KL, McGlashan DJ. 2006. Development and management of a coastal litter campaign: the voluntary coastal partnership approach. Marine Policy, 30: 189196.

Storrier KL, McGlashan DJ, Bonellie S, Velander K. 2007. Beach litter deposition at a selection of beaches in the Firth of Forth, Scotland. Journal of Coastal Research, 23(4): 813-822.

Sun X, Yang Z. 2008. Generalized McNemar's test for homogeneity of the marginal distributions. Statistics and Data Analysis, SAS Global Forum 2008.

Brink P, Lutchman I, Bassi S, Speck S, Sheavly S, Register K, Woolaway C. 2009. Guidelines on the Use of Market-based Instruments to Address the Problem of Marine Litter. Institute for European Environmental Policy (IEEP), Brussels, Belgium, and Sheavly Consultants, Virginia, USA. 60pp.

Teuten EM, Saquing JM, Knappe DRU, Barlaz MA, Jonsson S, Bjorn A, Rowland SJ, Thompson RC, Galloway TS, Yamashita R, Ochi D, Watanuki Y, Moore C, Hung Viet $\mathrm{P}$, Tana TS, Prudente M, Boonyatumanond R, Zakaria MP, Akkhavong K, Ogata Y, Hirai H, Iwasa S, Mizukawa K, Hagino Y, Imamura A, Saha M, Takada 
H. 2009. Transport and release of chemicals from plastics to the environment and to wildlife. Philosophical Transactions of The Royal Society, 364: 2027-2054.

The Marine Debris Information Forum, April 1-3 ${ }^{\text {rd }}$, Bethesda, Maryland 2008

THE MARINE DEBRIS RESEARCH, PREVENTION, AND REDUCTION ACT OF 2006, 33 U.S.C. SS 1951 et seq.

Thiel M, Hinojosa I, Vasquez N, Macaya E. 2003. Floating marine debris in coastal waters of the SE-Pacific (Chile). Marine Pollution Bulletin, 46: 224-231.

Thorton L, Jackson NL. 1998. Spatial and temporal variations in debris accumulation and composition on an estuarine shoreline, Cliffwood Beach, New Jersey, USA. Marine Pollution Bulletin, 36(9): 707-711.

Tudor DT, Williams AT, Randerson P, Ergin A, Earll RE. 2002. The use of multivariate statistical techniques to establish beach debris pollution sources. Journal of Coastal Research, 36: 716-725.

Tudor DT, Williams AT. 2004. Development of a 'Matrix Scoring Technique' to determine litter sources at a Bristol Channel beach. Journal of Coastal Conservation, 10(1-2): 119-127.

Turner A, Holmes L. 2010. Occurrence, distribution and characteristics of beached plastic production pellets on the island of Malta (central Mediterranean). Marine Pollution Bulletin, doi:10.1016/j.marpolbul.2010.09.027.

Twisk JWR. 2003. Applied longitudinal data analysis for epidemiology: a practical guide Cambridge University Press, Edinbourgh, UK

UNEP. 2009. Marine Litter: A Global Challenge. Nairobi: UNEP. 232 pp.

Uneputty PA, Evan SM. 1997. Accumulation of beach litter on islands of the Pulau Seribu Archipelago, Indonesia. Marine Pollution Bulletin, 34(8): 652-655.

U.S. Census Bureau: State and County QuickFacts. Data derived from Population Estimates, 2000. http://quickfacts.census.gov/qfd/states/06/06087.html 03/25/2010.

Velander KA, Mocogni M .1998. Maritime Litter and Sewage Contamination at Cramond Beach Edinburgh a Comparative Study. Marine Pollution Bulletin, 3(5): 385-389.

Velander KA, Mocogni M. 1999. Beach litter sampling strategies: is there a "best" method? Marine Pollution Bulletin, 38(12): 1134-1140.

Venables WN, Ripley BD. 2002. Modern Applied Statistics with S. fourth edition. New York: Springer Science + Business Media.

Vonesh EF, Chinchilli VM. 1997. Linear and Nonlinear Models for the Analysis of Repeated Measurements. New York: Marcel Dekker, Inc.

Watters DL, Yoklavich MM, Love MS, Schroeder DM. 2010. Assessing marine debris in deep seafloor habitats off California. Marine Pollution Bulletin, 60(1): 131138.

Williams AT, Tudor DT. 2001. Litter burial and exhumation: spatial and temporal distribution on a cobble pocket beach. Marine Pollution Bulletin, 42(11): 10311039.

Williams AT, Tudor DT, Randerson P. 2003. Beach litter sourcing in the Bristol Channel and Wales, U.K. Water Air Soil Pollution, 143: 387-408.

Wong CS, Green DR, Cretney WJ. 1974. Quantitative tar and plastic waste distribution in the Pacific Ocean. Nature, 247: 30-32. 
Yamashita R, Tanimura A. 2007. Floating plastic in the Kuroshio Current area, western North Pacific Ocean. Marine Pollution Bulletin, 54: 464-488.

Zurr AF, Ieno EN, Walker NJ, Saveliev AA, Smith GM. 2009. Mixed Effects Models and Extensions in Ecology with R. New York: Springer. 


\section{APPENDIX A}

\section{BEACH-BASED SURVEYS: BACKGROUND AND POLICY IMPLICATIONS}

\section{How do we assess marine debris and why}

Manmade litter such as derelict fishing gear, food wrappers, beverage bottles, cigarette butts, bottle caps, and resin pellets, are examples of marine debris (Sheavly 2007). Floating debris tends to concentrate on beaches (McDermid and McMullen 2004; Cochran et al. 2009), coastal and oceanic surface waters (Thiel et al. 2003), riverine systems (Araújo and Costa 2007), and on the seafloor due to oceanic currents (Galgani et al. 1995; Moore and Allen 2000). Literature on the sources and distribution of plastics indicate its worldwide predominance (Derraik 2002). Methods for assessing marine debris include ocean-based boat surveys (Matsumura and Nasu 1997; Aliani et al. 2003; Thiel et al. 2003; Shiomoto and Kameda 2005), beach surveys (Rees and Pond 1995; McDermid and McMullen 2004; Corcoran et al. 2009), and aerial surveys (LeckeMitchell and Mullin 1997; Pichel et al. 2007). It is necessary to conduct surveys of this floating plastic pollution because it does not completely biodegrade, causes ecological harm, and travels far (Kubota and Takayama 2005; Moore 2008). Photo-degradation (solar-caused chemical breakdown) of plastics is not well studied though it is thought much of this breakdown occurs at sea (Shaw and Day 1994). Carpenter and Smith (1972) have alluded to the weathering and fragmentation that occurs to plastic in the ocean, suggesting that as plastic becomes more fragmented its quantity vastly multiplies, thus endangering the marine environment. Beach surveys, particularly on remote beaches, can be useful as indicators of the amount of fragmented plastic in the marine environment (Ribic et al. 1992, McDermid and McMullen 2004)

\section{Ecological threats caused by marine debris}

Floating marine debris (FMD) presents numerous ecological threats (Derriak 2002) and requires both boat-based and beach surveys for monitoring purposes (Dixon and Cooke 1977, Moore 2008). Similar to naturally occurring flotsam, marine debris serves as a vehicle for the transport of non-native sessile organisms such as barnacles, 
tunicates, diatoms, and hydras (Carpenter and Smith 1972; Barnes and Milner 2005). Marine debris as a vector for travel has been associated with the spread of harmful algal blooms (Maso et al. 2003). Floating litter provides a pathway for non-native invasive species to populate foreign harbors, unbalancing local fisheries by potentially threatening commercially valuable species (Brink et al. 2009). The accidental ingestion of floating litter by several marine species is also an issue. For example, a necropsy of a minke whale, Balaenoptera acutorostrata, produced $720 \mathrm{~g}$ of plastic bag in its stomach and nothing else (Pierrepont et al. 2005). Ingested plastics can easily enter the marine environment postmortem, perpetuating a cycle of death. The chemical leaching of PCBs into the fatty tissues and eggs of seabirds has also been studied (Ryan et al. 1988). The pervasiveness of plastics in the marine environment is also indicated from research on seabirds that used plastic debris as nesting material (Hartwig et al. 2007).

Sea turtles commonly mistake plastic bags for prey such as jellyfish. Ingestion of debris by sea turtles results in decreased growth rates, depleted energy reserves, reduced reproductive output, and decreased survivorship (McCauly and Bjorndal 1999). In addition, mortalities of whale species have been documented as a result of impaired immune systems due to the occlusion of the stomach caused by ingesting plastic objects (Pierrepont et al. 2005; Stamper et al. 2006; Meirelles and Barros 2007). Young sea lions have become entangled in derelict fishing gear, packing straps, plastic bags, rope and rubber o-rings (Goldstein et al. 1999). Less studied are invertebrates. It has been found that four species of deposit-feeding and suspension-feeding sea slugs were shown to prefer nylon and PVC fragments found in their food source compared to naturally found algae (Graham and Thompson 2009). FMD also causes fatalities through entanglement in active or discarded fishing gear (Hofman 1990). Two species directly affected by entanglement are the North Atlantic right whale (Levesque 2009) and the Hawaiian monk seal (Boland and Donohue 2003). It is crucial to study the distribution and abundance of harmful FMD such as plastics on surface waters because of their proximity to marine organisms and their food sources.

Potential economic losses caused by marine debris 
Studying beach litter is relevant for economic reasons as well. People use beaches for recreational purposes and scenery (Blakemore and Williams 2008). On beachscapes, the accumulation of trash is unsanitary, an eyesore, and can deter beach visitors (Balance and Williams 2008). Aesthetics and cleanliness have been documented as the most important factor in influencing choice of beach to visit (Smith et al. 1997, Ballance et al. 2000, Blakemore and Williams 2008). Trash produced both on land and discarded at sea can significantly impact coastal economies, causing damage to boats by fouling, striking, or becoming entangled in motors and fishing gear. Ecosystem services can be reduced as a result of marine debris destroying coastal and marine habitat (Brink et al. 2009). Ensnared debris can suffocate intertidal flora and fauna which can lead to habitat destruction and decreased ecosystem health (Brink et al. 2009). Additionally, alien species introduction can have a damaging economic effect through loss of ecosystem function (Brink et al. 2009).

Plastics in the coastal environment: potential threats to human health

The ability of plastic compounds to attract micro-pollutants and even trace metals has been demonstrated in several studies (Mato et al. 2001; Endo et al. 2005; Teuten et al. 2007; Teuten et al. 2009; Turner and Holmes 2010). Studies have shown that the petroleum based chemicals that plastic is composed of can amplify environmental toxicity through the surface absorption and adsorption of DDT, PCB, flame retardants, and other pesticides (Teuten et al. 2009). In the past two decades, small fragmented plastics including pre-production resin pellets have increased in quantity globally (Browne et al. 2007; Barnes et al. 2009). For example, high levels of DDT and PCBs have been detected adsorbed onto resin pellets on the West Coast, USA (Ogata et al. 2009). The harmful effects of these contaminants are well researched on wildlife and humans and include endocrine disruption (Maffini et al. 2006; Crain et al. 2007). Disruption to the human endocrine system can cause alterations in reproductive health and cancer; these effects were found to be induced by estrogen-mimic bisphenol-A (BPA) accumulation in humans (Maffini et al. 2006). Bisphenol-A is commonly used in manufacturing plastic food and beverage containers (Maffini 2006). 
Marine debris survey methodologies: sand versus sea

There has been debate over survey methods, specifically the appropriateness and accuracy of a beach survey verses a boat survey. Thiel et al. (2003) asserts that boatbased surveys provide a better quantitative estimate of marine debris. Thiel et al. (2003) and Shiomoto and Kameda (2005) claim that beach surveys only capture a fraction of the types of marine debris that strand on shore. They contend that beach surveys are a good way to visualize composition of debris, but data from beach surveys are just an approximation (Thiel et al. 2003). Ocean currents are dynamic systems affecting dispersal of FMD (Wong 1974), thus items found during beach clean-ups may not be representative of items found at sea (Thiel et al. 2003). For instance, fishing gear that is washed onto a beach may not be directly proportional to the total quantity of derelict gear floating in the North Pacific (Day et al. 1990).

Rees and Pond (1995) discuss the disadvantages of boat-based surveys, suggesting that a number of confounding factors introduced by being on the water can create unreliable estimates of marine debris. They assert that boat-based surveys can produce too many inaccuracies caused by variation in ship speed or wind condition. Missing items or counting the same item twice during transect can also confound results (Rees and Pond 1995). Adding to this argument, boat-based researchers (Wong 1974; Morris 1980; Matsumura and Nasu 1992; Yamashita and Tanimura 2007) often are unable to control the pre-existing route or transect taken by their vessel due to the pointto-point travel of the boat. Rees and Pond (1995) stressed that these studies did not represent a true estimate of debris because the boat was already headed toward a destination thus the researcher could not dictate the sampling area. Rees and Pond (1995) suggest boat-based surveys are too expensive, weather reliant, and rely on clear visibility and suggest that beach surveys are cost efficient, require little equipment, and less experienced surveyors can be used.

Historical context: beach based surveys 
Beach surveys have typically focused on macro debris, items larger than $2.5 \mathrm{~cm}$ (Ribic 1992, Ryan et al. 2009). The first beach surveys on trash assessment were conducted in the early 1970s and were connected to hypotheses regarding ocean circulation (Scott 1972, Cunell 1973). Scott (1972) was one of the first scientists to survey remote beaches and come to the conclusion that most plastic debris is deposited on shore via ocean currents. Dixon and Cooke (1977) asserted that the lack of information on marine debris hindered scientists' ability to adequately quantify and monitor the problem. Through the development of survey methods (following the stand line to walking along stratified transects), researchers were able to sample for smaller items, thus corroborating the findings of boat-based surveys (Carpenter and Smith's 1972, Gregory 1978), specifically noting the presence of plastic resin pellets. However, due to the lack of abundance, distribution, and categorical information on beach litter, scientists focused their beach survey efforts globally, including Japan, Russia, Indonesia, Brazil, United Kingdom, and Australia (Golick and Gertner 1992, Uneputty and Evan 1997, Velander and Mocogni 1998, Kusui and Noda 2003).

\section{Variations in beach survey methodologies}

Most beach surveys use random sampling that includes stratified transects between the shoreline and back beach (Thorton and Jackson 1998, Velander and Mocogni 1999, Moore et al. 2001). Stratification within a survey enables greater coverage of area being sampled and is accomplished by spatially separating transect lines (Thorton and Jackson 1998) which may be in the form of belt or strip transects (Frost and Cullen 1997; Cunningham and Wilson 2003; Storrier et al. 2007). Random sampling of litter occurs along these transects, which refers to a direct line or swath of area of specified distance which functions as a vector for data collection. Examples of belt transects (swath of area) are from Oigman-Pszczol and Creed's (2007) study of Brazilian beaches, where they surveyed a $4 \mathrm{~m}$ wide transect along the stand line of 10 different beaches. Thorton and Jackson (1998) used a $5 \mathrm{~m}$ x $10 \mathrm{~m}$ belt transects spaced $10 \mathrm{~m}$ apart . The length of transects along the beach vary from 47 to 818 meters (Oigman-Pszczol and Creed 2007). Examples of strip transects (line transects) are from Cunningham and 
Wilson's (2003) study in Australia where three 50m strip transects were used to sample from lower, middle, and upper stratum of the beach. Yet other methods involve systematically removing litter from an entire beach over time (Edyvane et al. 2004). Despite choice of methodology, Storrier and McGlashan 2006 and Ryan et al. (2009) claim that the above methods frequently fail to spot meso-scale debris, items smaller than $2 \mathrm{~cm}$, and in so doing misrepresent the true abundance of beach litter.

Few surveys sample buried litter which can also require the use of quadrats and sieves to sample deposited litter (Kusui and Noda 2003, McDermid and McMullen 2004). For example McDermid and McMullen (2004) used small quadrats $(61 \mathrm{~cm} \times 61 \mathrm{~cm})$ to designate where to sample buried debris. There is a lack of statistical analysis by researchers of beach litter distribution and abundance (Thornton and Jackson 1998, Moore et al. 2001, Edyvane et al. 2004, McDermid and McMullen 2004, Corcoran et al. 2009). Statistical tests such as $Z$-tests have been used to compare litter proportions over time (Velander and Mocogni 1998). Oigman-Pszczol and Creed (2007) used several tests including Levene's test to test the homogeneity of variance between beach sites and litter abundance. Cunningham and Wilson (2003) used ANOVA to test differences in total litter between beach location, beach zone, and transects, and post hoc they used Tukey's HSD tests to identify specific differences between the aforementioned variables.

Considered to be more robust, principle component analysis and cluster analysis are also used to examine patterns among beach litter and survey sites (Tudor et al. 2002, Williams et al 2003). Proposing statistical models that include physical drivers as the parameters that drive litter abundance has met success (Ribic et al. 2010) Researchers are now able to suggest the likelihood of the best fitting model given the predictive variables through model comparison using Akaike's Information Criterion (AIC) (Burnham and Anderson 2002). Additionally, AIC is used in model selection for generating hypothesis on various environmental drivers affecting amounts of litter (Ribic et al. 2010). This use of multivariate analysis as an inductive, non-experimental approach and is supported because this type of analysis helps to generate hypotheses about the causality of beach litter rather than directly testing hypotheses against a multitude of confounding environmental variables (Tudor and Williams 2004). 


\section{Conclusion}

Marine debris has many sources and is affected by a variety of environmental drivers. It has been found that as plastics become fragmented they cause a multitude of problems in the marine environment. Beach surveys provide the quantitative data necessary to assess the magnitude of this problem by measuring distribution, abundance, accumulation, and category using well established methods. Continuing to study abundance of marine debris is paramount and will benefit from more expansive methodologies. Surveying using belt transects can help identify larger pieces of plastic and are useful for the quantification of debris dispersal. However, belt transects can underestimate the abundance of smaller plastics and more precise measurements of abundance are obtained from collecting plastic fragments using a quadrat or sieve. Utilizing survey methods that incorporate collecting large and small debris will ensure higher accuracy in results and assist sciences ability to inform policy. In order to abate the widespread issue of marine debris more effort by beach surveying must take place. 


\section{APPENDIX B}

\section{DIAGNOSTIC STATISTICAL ANALYSIS}

\section{Diagnostic Statistical Analysis}
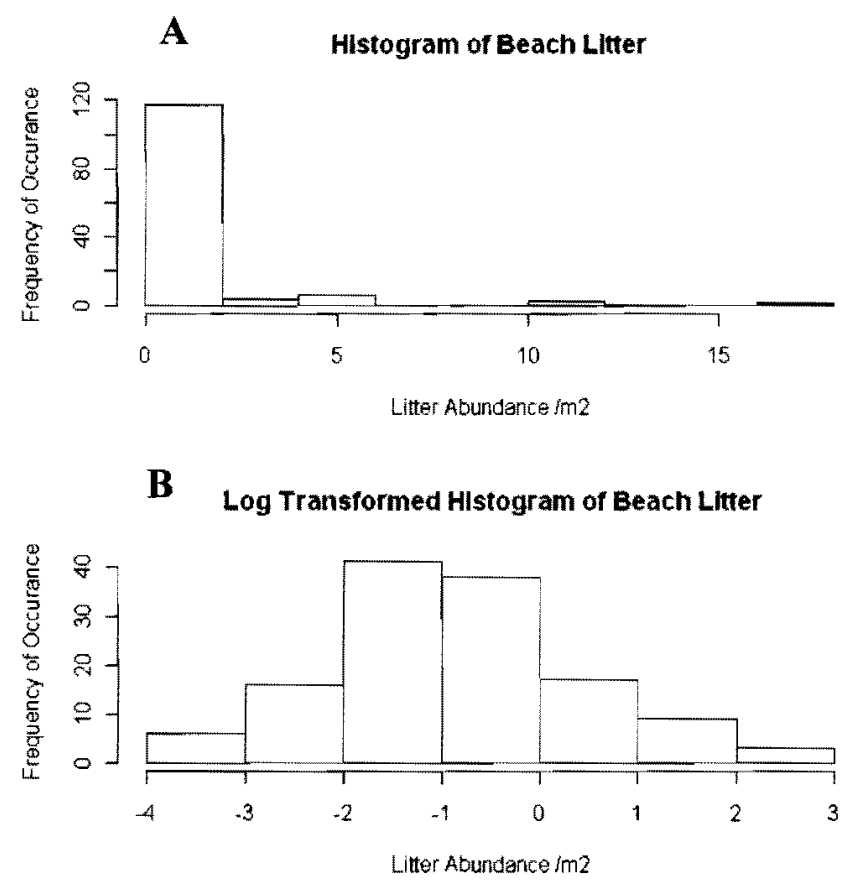

Figure 5. The frequency of occurrence of litter abundance (A) and the resultant log transformation of litter abundance (B). 

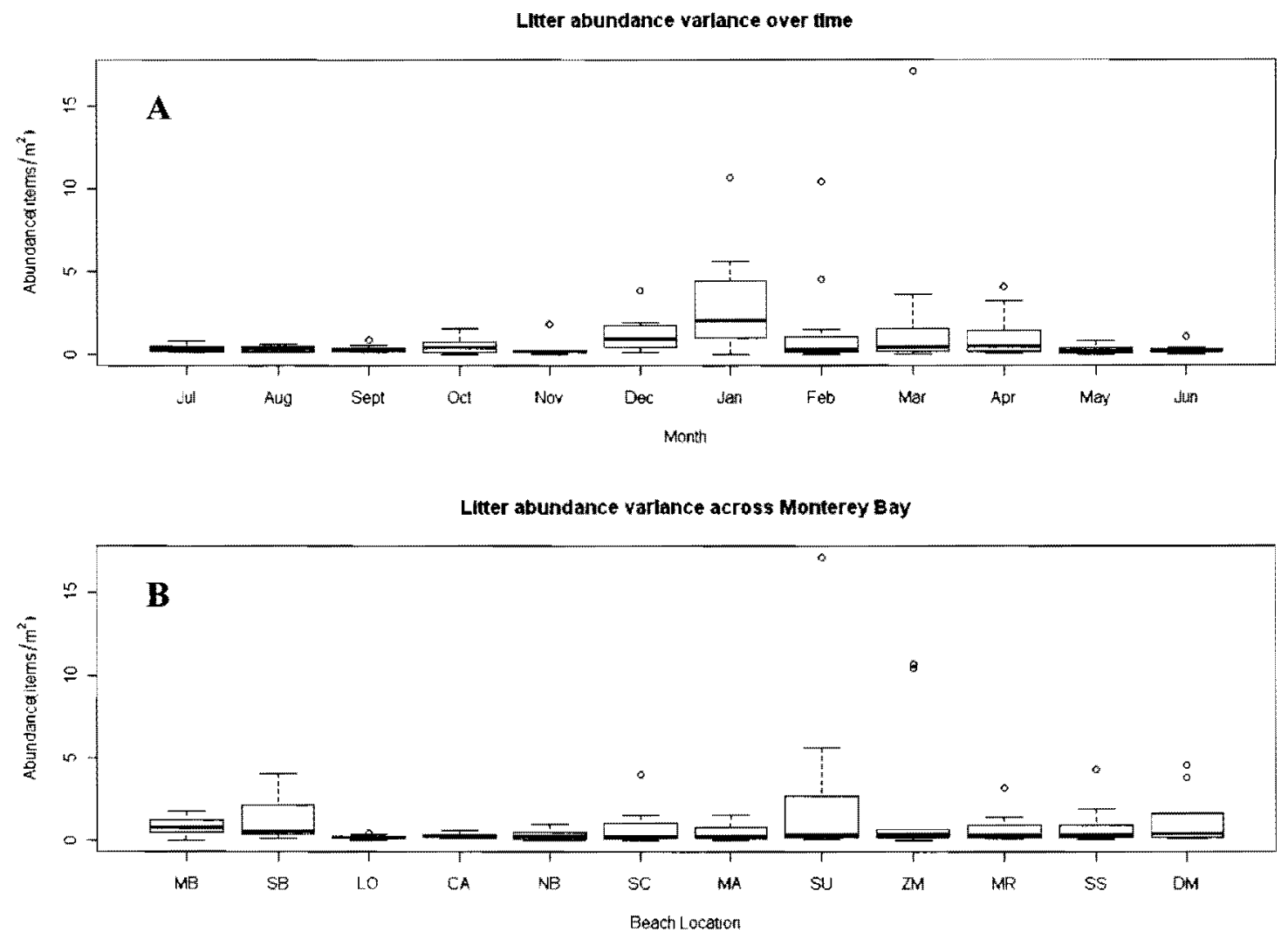

Figure 6A and B. A. The distribution of the untransformed litter abundance from July 2009 to June 2010. B. The distribution of the untransformed litter abundance across all 12 study sites (from North to South in the Bay). 


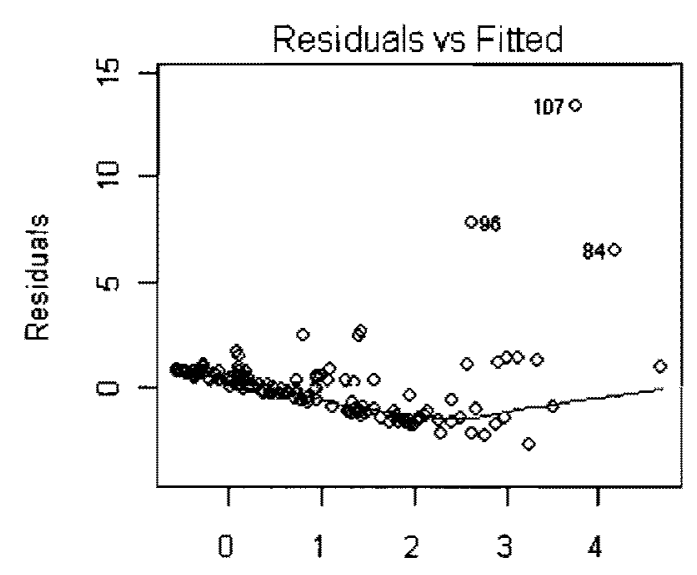

Fitted values

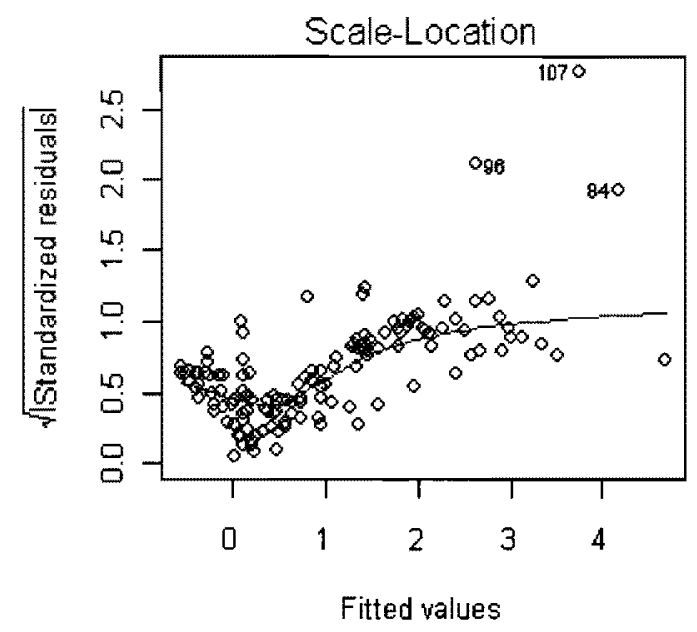

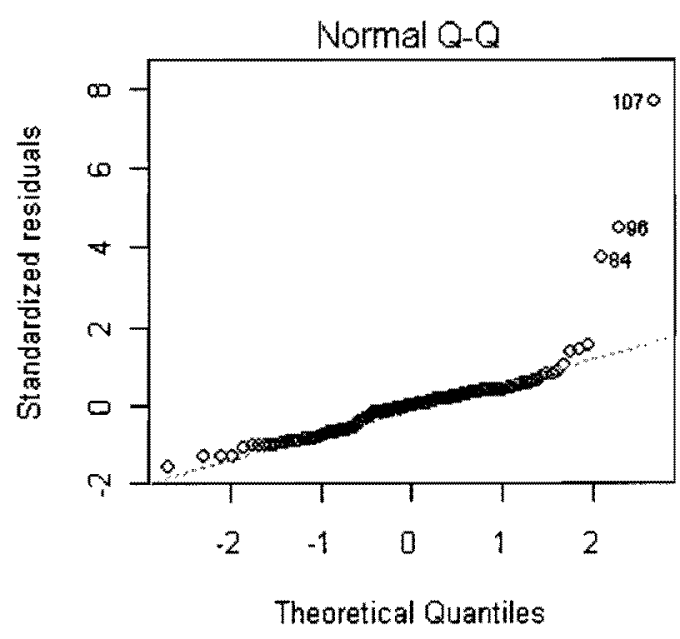

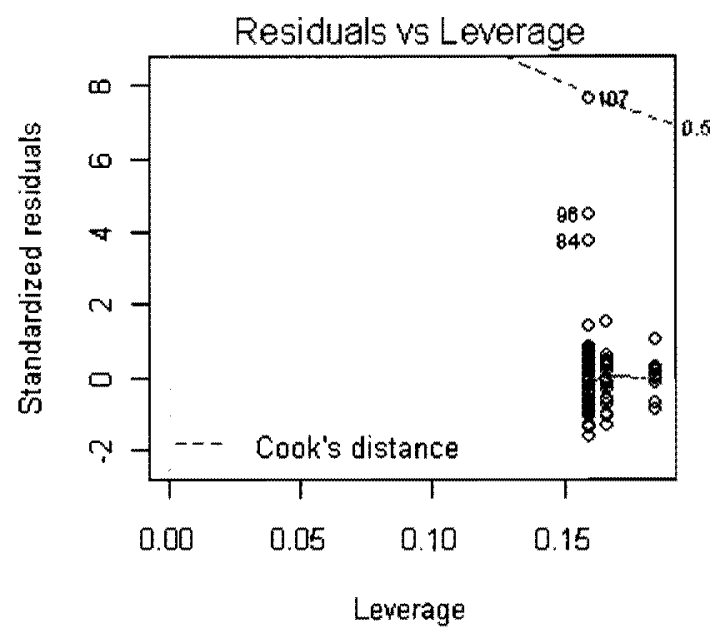

Figure 7. Regression diagnostics evaluating model assumptions on $M_{1}$, showing four validation graphs identifying the fitted residuals to the model (top left), Normal Q$Q$ (distribution of standardized residuals) (top right), Heteroscedasticity (trend in dispersion of standardized residuals) (bottom left), and Residuals vs. Leverage (influence of each observation on the regression coefficient) (bottom right) (Dalgaard 2008). 

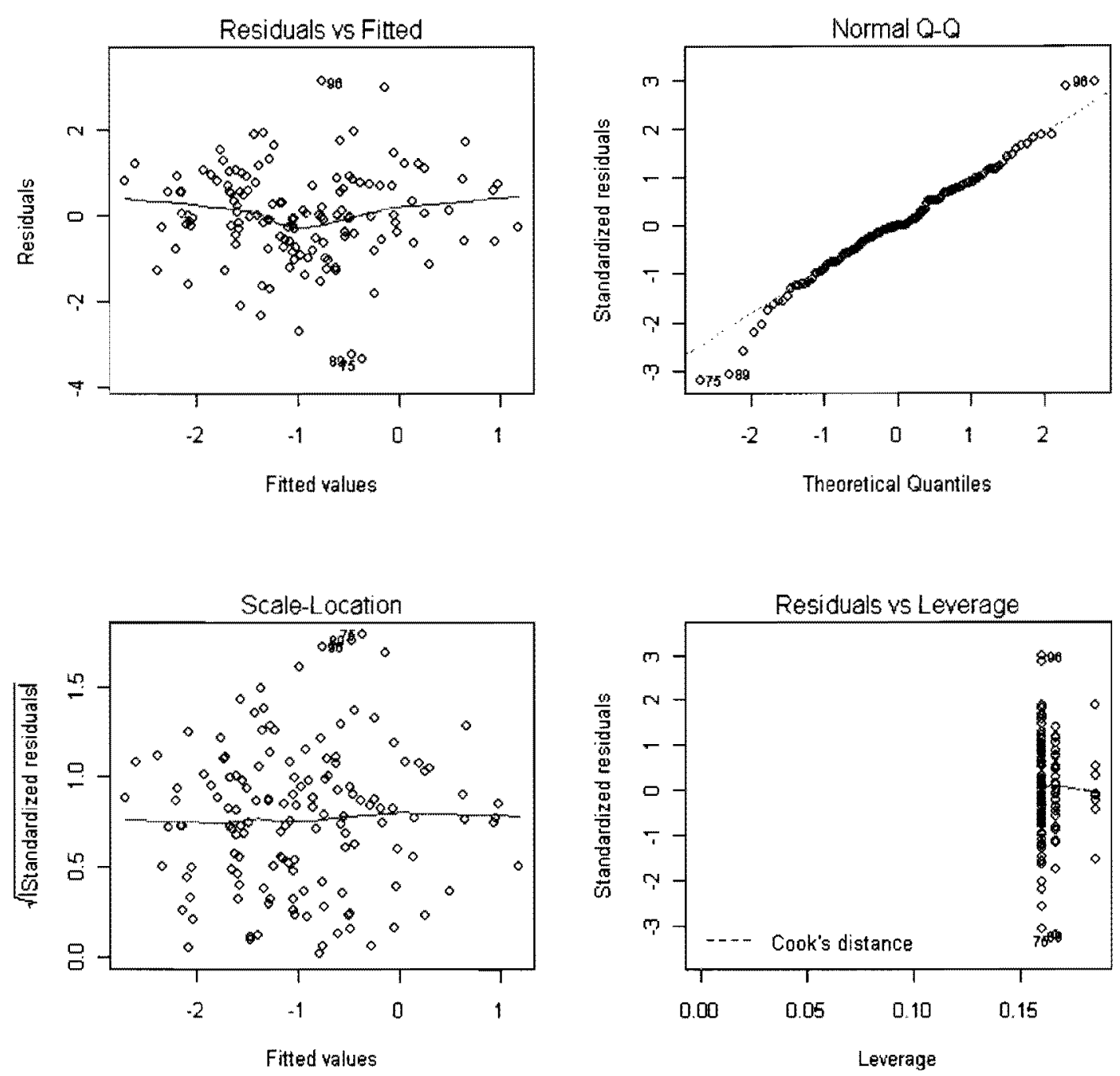

Figure 8. Regression diagnostics evaluating model assumptions on $M_{1}(\log$ transformed litter abundance), showing four validation graphs identifying the fitted residuals to the model (top left), Normal Q-Q (distribution of standardized residuals) (top right), Homoscedasticity (trend in dispersion of standardized residuals) (bottom left), and Residuals vs. Leverage (influence of each observation on the regression coefficient) (bottom right) (Dalgaard 2008). 


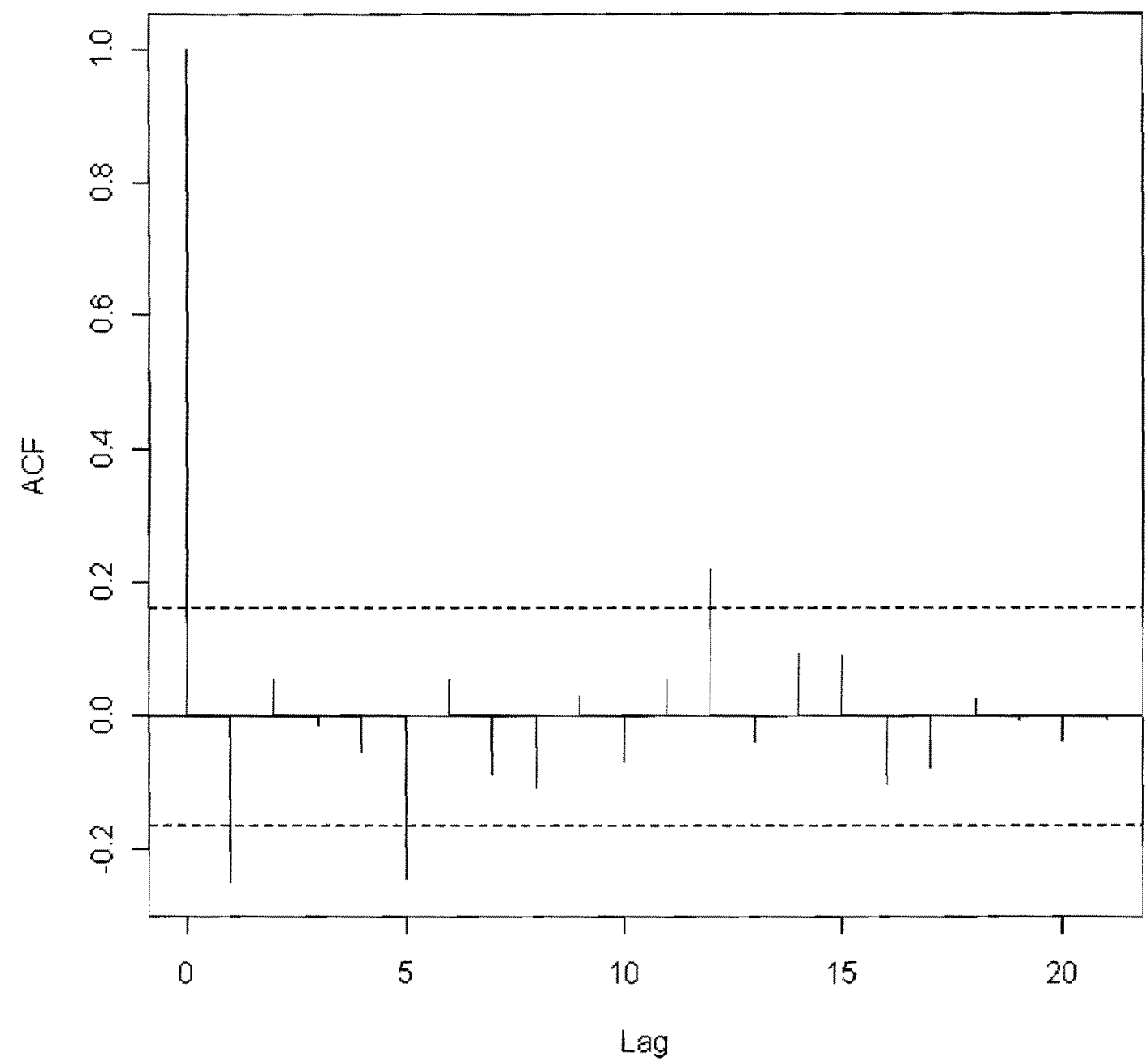

Figure 9. Auto-correlation plot for $\mathrm{Model}_{4}$ (log transformed litter abundance data). Vertical lines represent different separation time or time lags and the length of line indicates significant correlation (extending past $\mathbf{- 0 . 2}$ or 0.2 ). Note there is some indication of violation of independence due to time lag lengths (Zuur et al. 2009). 


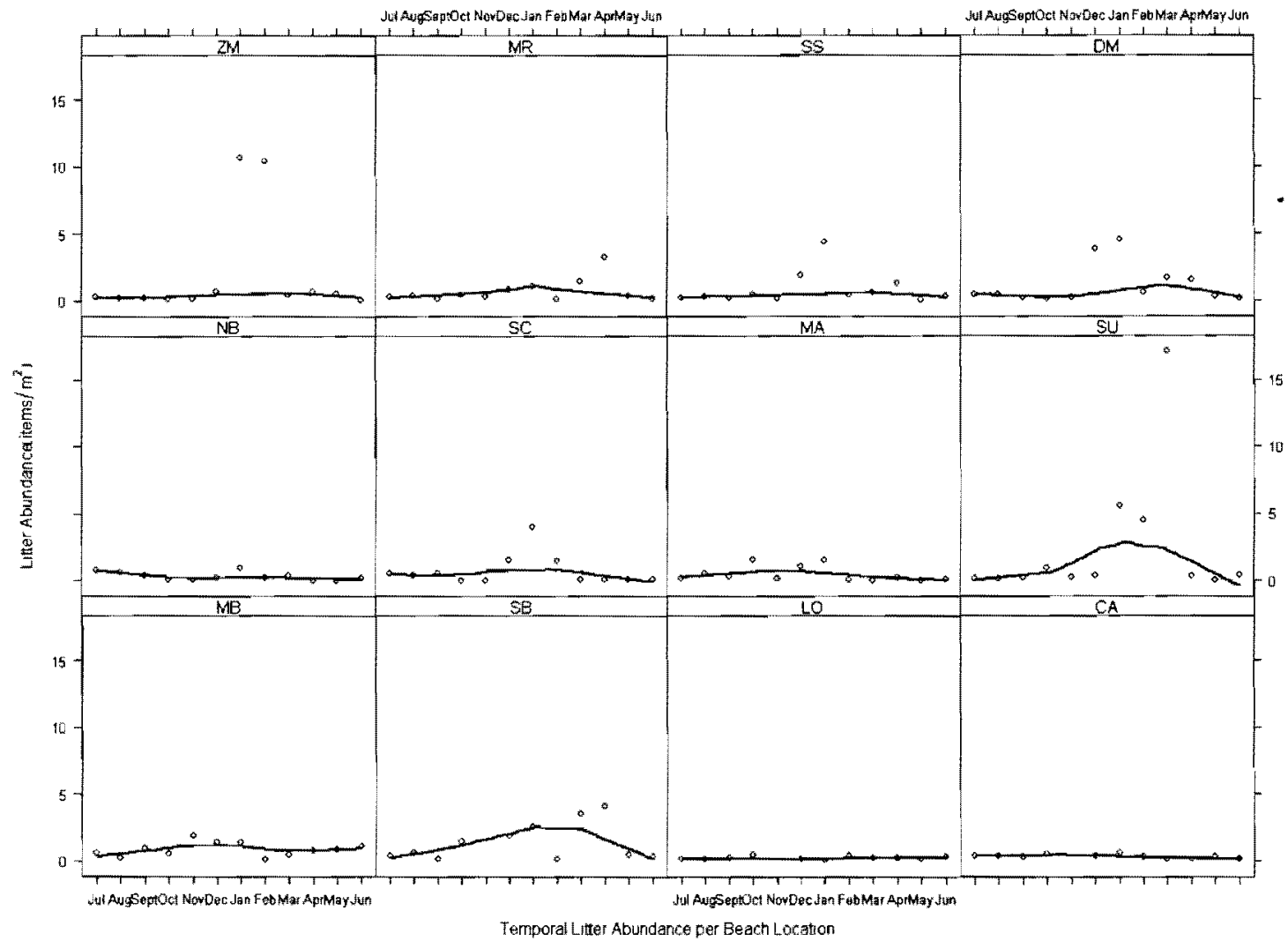

Figure 10. The temporal distribution of untransformed litter abundance per individual beach location across months. 


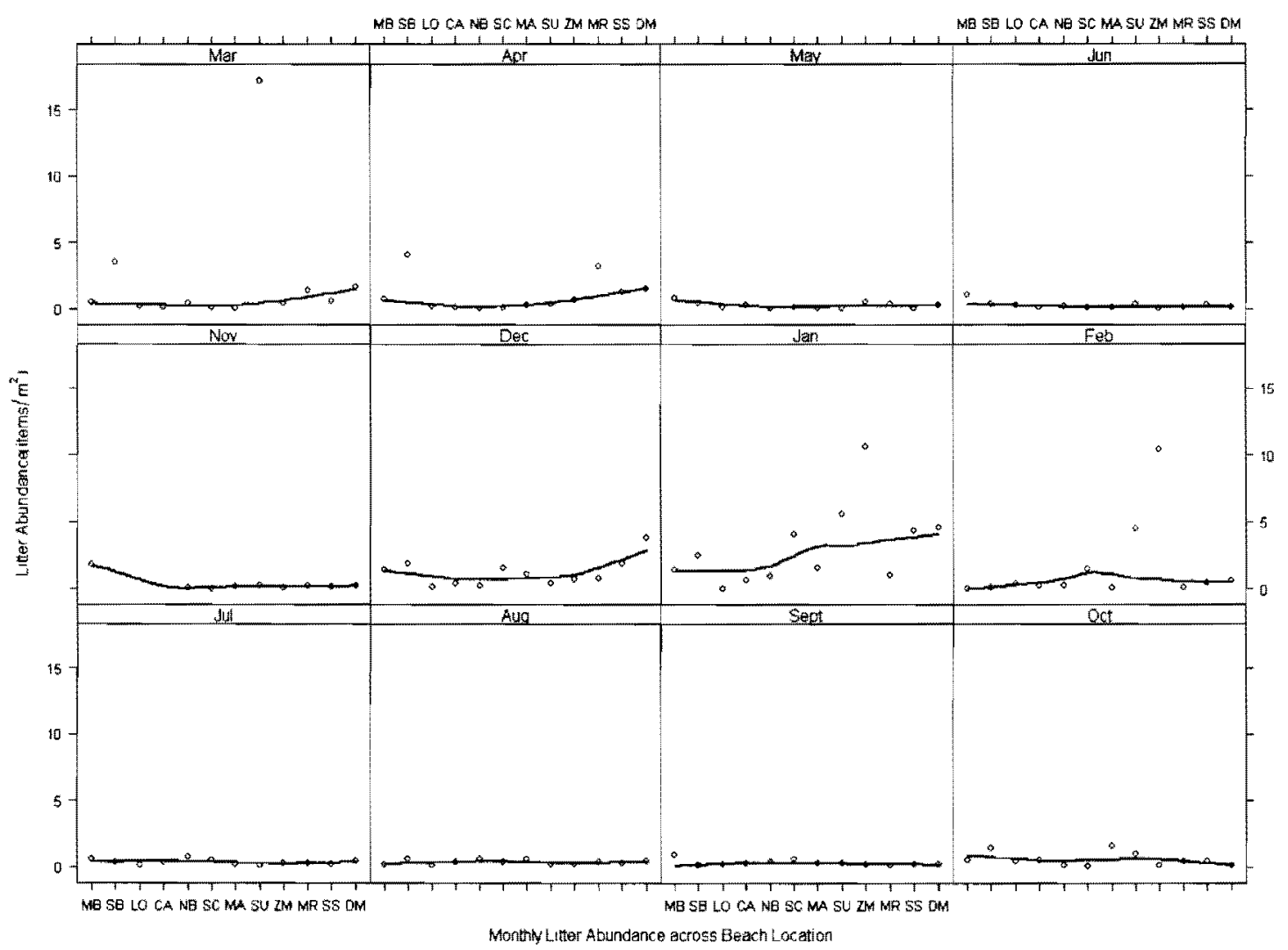

Figure 11. The spatial distribution of untransformed litter abundance per each survey month across beach locations. 
APPENDIX C

\section{TABLES OF CATEGORICAL DATA}

Table 5. Count of general items by category per beach location.

General Marine Debris Categories

Metal Cig. Butt Fabric Fertilizer Pellet Fishing Gear Food Wrapper Fragmented Plastic Glass Other Paper/Wood Plastic Product Polystyrene Rubber

\begin{tabular}{|c|c|c|c|c|c|c|c|c|c|c|c|c|c|}
\hline Main Beach & 14 & 74 & 10 & 0 & 0 & 42 & 86 & 4 & 0 & 44 & 66 & 114 & 4 \\
\hline Seabright & 7 & 51 & 6 & 3 & 2 & 35 & 70 & 19 & 1 & 39 & 49 & 350 & 5 \\
\hline Live Oak & 1 & 21 & 4 & 0 & 0 & 1 & 19 & 2 & 0 & 22 & 15 & 18 & 4 \\
\hline Capitola & 4 & 22 & 2 & 1 & 0 & 17 & 48 & 4 & 1 & 11 & 13 & 48 & 2 \\
\hline New Brighton & 3 & 24 & 4 & 0 & 1 & 34 & 50 & 4 & 0 & 26 & 22 & 53 & 16 \\
\hline Sea Cliff & 3 & 24 & 9 & 0 & 2 & 32 & 49 & 7 & 3 & 22 & 31 & 241 & 3 \\
\hline Manresa & 10 & 24 & 6 & 2 & 2 & 26 & 69 & 1 & 2 & 33 & 21 & 82 & 4 \\
\hline Sunset & 6 & 18 & 1 & 0 & 13 & 21 & 714 & 3 & 0 & 20 & 213 & 147 & 4 \\
\hline Zmudowski & 13 & 14 & 0 & 63 & 2 & 4 & 43 & 8 & 0 & 9 & 41 & 845 & 1 \\
\hline Marina & 4 & 19 & 13 & 0 & 5 & 24 & 32 & 18 & 0 & 10 & 33 & 209 & 8 \\
\hline Seaside & 8 & 19 & 3 & 0 & 1 & 28 & 163 & 25 & 3 & 24 & 20 & 178 & 5 \\
\hline Del Monte & 11 & 39 & 1 & 0 & 0 & 10 & 291 & 10 & 2 & 26 & 29 & 178 & 0 \\
\hline Percentage & $1 \%$ & $6 \%$ & $1 \%$ & $1 \%$ & $0 \%$ & $5 \%$ & $27 \%$ & $2 \%$ & $0 \%$ & $5 \%$ & $9 \%$ & $41 \%$ & $1 \%$ \\
\hline
\end{tabular}


Table 6. Count of plastic items by category per beach location.

\begin{tabular}{|c|c|c|c|c|c|c|c|c|c|c|}
\hline & \multicolumn{10}{|c|}{ Plastic Marine Debris Categories } \\
\hline & Resin Pellet & Beverage Item & Bottle Cap & Firecracker & Food Wrapper & Fragmented Plastic & Misc. & Plastic Bag & Straw Wrapper & Munition \\
\hline Main Beach & 2 & 1 & 8 & 4 & 36 & 86 & 16 & 4 & 21 & 1 \\
\hline Seabright & 0 & 0 & 6 & 7 & 35 & 70 & 21 & 1 & 7 & 2 \\
\hline Live Oak & 0 & 1 & 5 & 0 & 4 & 19 & 2 & 4 & 2 & 0 \\
\hline Capitola & 0 & 3 & 2 & 0 & 11 & 48 & 5 & 2 & 4 & 0 \\
\hline New Brighton & 0 & 0 & 4 & 3 & 25 & 50 & 6 & 5 & 6 & 0 \\
\hline Sea Cliff & 3 & 1 & 10 & 6 & 21 & 49 & 6 & 3 & 6 & 0 \\
\hline Manresa & 9 & 2 & 4 & 0 & 12 & 69 & 6 & 0 & 12 & 0 \\
\hline Sunset & 175 & 3 & 8 & 11 & 20 & 714 & 7 & 0 & 6 & 1 \\
\hline Zmudowski & 11 & 1 & 4 & 2 & 2 & 43 & 6 & 5 & 13 & 0 \\
\hline Marina & 2 & 0 & 3 & 0 & 24 & 32 & 8 & 7 & 11 & 0 \\
\hline Seaside & 4 & 2 & 4 & 0 & 17 & 163 & 7 & 0 & 6 & 0 \\
\hline Del Monte & 3 & 1 & 7 & 1 & 8 & 291 & 8 & 0 & 7 & 1 \\
\hline Percentage & $9 \%$ & $1 \%$ & $3 \%$ & $1 \%$ & $9 \%$ & $68 \%$ & $4 \%$ & $1 \%$ & $4 \%$ & $0 \%$ \\
\hline
\end{tabular}


Table 7. Count of general items by category per month.

General Marine Debris Categories

Metal Cig. Butt Fabric Fertilizer Pellet Fishing Gear Food Wrapper Frag. Plastic Glass Other Paper/Wood Plastic Product Polystyrene Rubber

\begin{tabular}{|c|c|c|c|c|c|c|c|c|c|c|c|c|c|}
\hline July & 8 & 69 & 6 & 0 & 1 & 48 & 38 & 13 & 2 & 35 & 51 & 45 & 15 \\
\hline August & 3 & 58 & 14 & 0 & 5 & 49 & 45 & 7 & 1 & 47 & 42 & 55 & 5 \\
\hline September & 8 & 53 & 10 & 0 & 0 & 40 & 49 & 3 & 2 & 58 & 41 & 32 & 9 \\
\hline October & 10 & 20 & 5 & 0 & 0 & 31 & 56 & 2 & 0 & 28 & 16 & 97 & 4 \\
\hline November & 6 & 21 & 1 & 0 & 0 & 25 & 17 & 1 & 0 & 11 & 18 & 20 & 2 \\
\hline December & 8 & 31 & 1 & 0 & 3 & 38 & 160 & 12 & 1 & 17 & 35 & 256 & 6 \\
\hline January & 8 & 13 & 1 & 22 & 3 & 6 & 361 & 8 & 0 & 3 & 68 & 1010 & 2 \\
\hline February & 4 & 7 & 0 & 42 & 2 & 7 & 92 & 18 & 2 & 8 & 19 & 523 & 3 \\
\hline March & 9 & 11 & 3 & 3 & 10 & 17 & 627 & 22 & 0 & 34 & 164 & 156 & 3 \\
\hline April & 2 & 34 & 14 & 2 & 1 & 0 & 126 & 12 & 2 & 21 & 52 & 238 & 2 \\
\hline May & 12 & 16 & 3 & 0 & 2 & 6 & 35 & 5 & 0 & 7 & 26 & 9 & 3 \\
\hline June & 6 & 16 & 1 & 0 & 1 & 7 & 28 & 2 & 2 & 17 & 21 & 22 & 2 \\
\hline Percentage & $1 \%$ & $6 \%$ & $1 \%$ & $1 \%$ & $0 \%$ & $5 \%$ & $27 \%$ & $2 \%$ & $0 \%$ & $5 \%$ & $9 \%$ & $41 \%$ & $1 \%$ \\
\hline
\end{tabular}


Table 8. Count of plastic items by category per month.

Plastic Marine Debris Categories

Resin Pellet Bev. Item Bottle Cap Fire Cracker Food Wrapper Frag. Plastic Misc. Item Plastic Bag Straw/Wrapper Munition

\begin{tabular}{|c|c|c|c|c|c|c|c|c|c|c|}
\hline July & 0 & 3 & 10 & 11 & 35 & 38 & 14 & 10 & 9 & 0 \\
\hline August & 0 & 3 & 9 & 8 & 31 & 45 & 9 & 3 & 13 & 0 \\
\hline September & 0 & 1 & 12 & 3 & 22 & 49 & 11 & 3 & 14 & 0 \\
\hline October & 1 & 1 & 6 & 0 & 20 & 56 & 8 & 2 & 6 & 0 \\
\hline November & 0 & 0 & 2 & 1 & 16 & 17 & 7 & 0 & 9 & 0 \\
\hline December & 7 & 1 & 8 & 2 & 28 & 160 & 6 & 2 & 11 & 0 \\
\hline January & 50 & 0 & 2 & 0 & 6 & 361 & 2 & 0 & 11 & 2 \\
\hline February & 8 & 3 & 2 & 0 & 5 & 92 & 2 & 2 & 4 & 1 \\
\hline March & 138 & 2 & 3 & 9 & 15 & 627 & 5 & 3 & 6 & 0 \\
\hline April & 1 & 1 & 0 & 0 & 18 & 126 & 24 & 4 & 4 & 1 \\
\hline May & 3 & 0 & 7 & 0 & 9 & 35 & 1 & 2 & 9 & 1 \\
\hline June & 1 & 0 & 4 & 0 & 10 & 28 & 9 & 0 & 5 & 0 \\
\hline Percentage & $9 \%$ & $1 \%$ & $3 \%$ & $1 \%$ & $9 \%$ & $68 \%$ & $4 \%$ & $1 \%$ & $4 \%$ & $0 \%$ \\
\hline
\end{tabular}



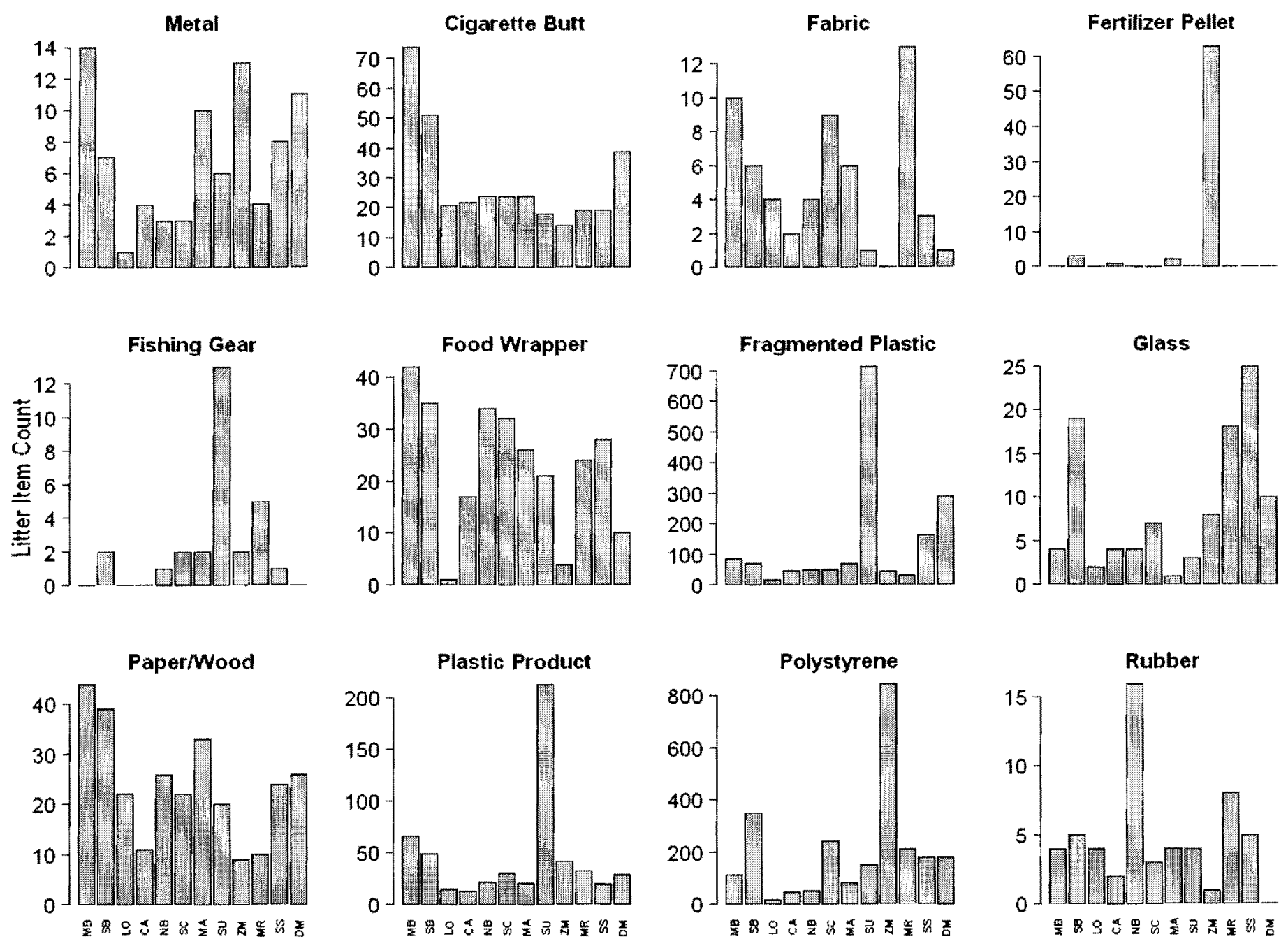

Figure 12. The item count of 12 general litter categories across beach locations. 

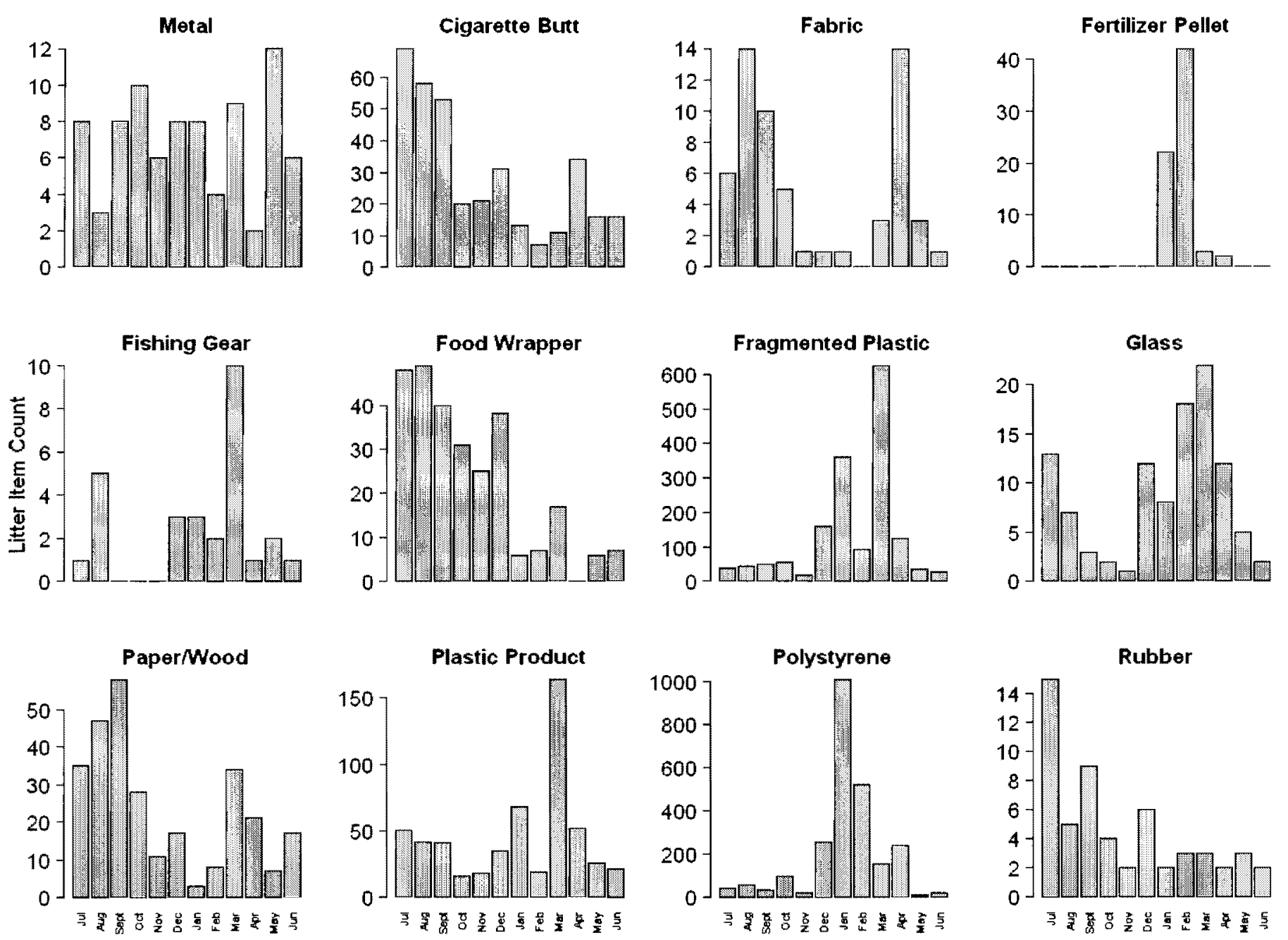

Figure 13. The item count of 12 general categories of litter across survey months. 

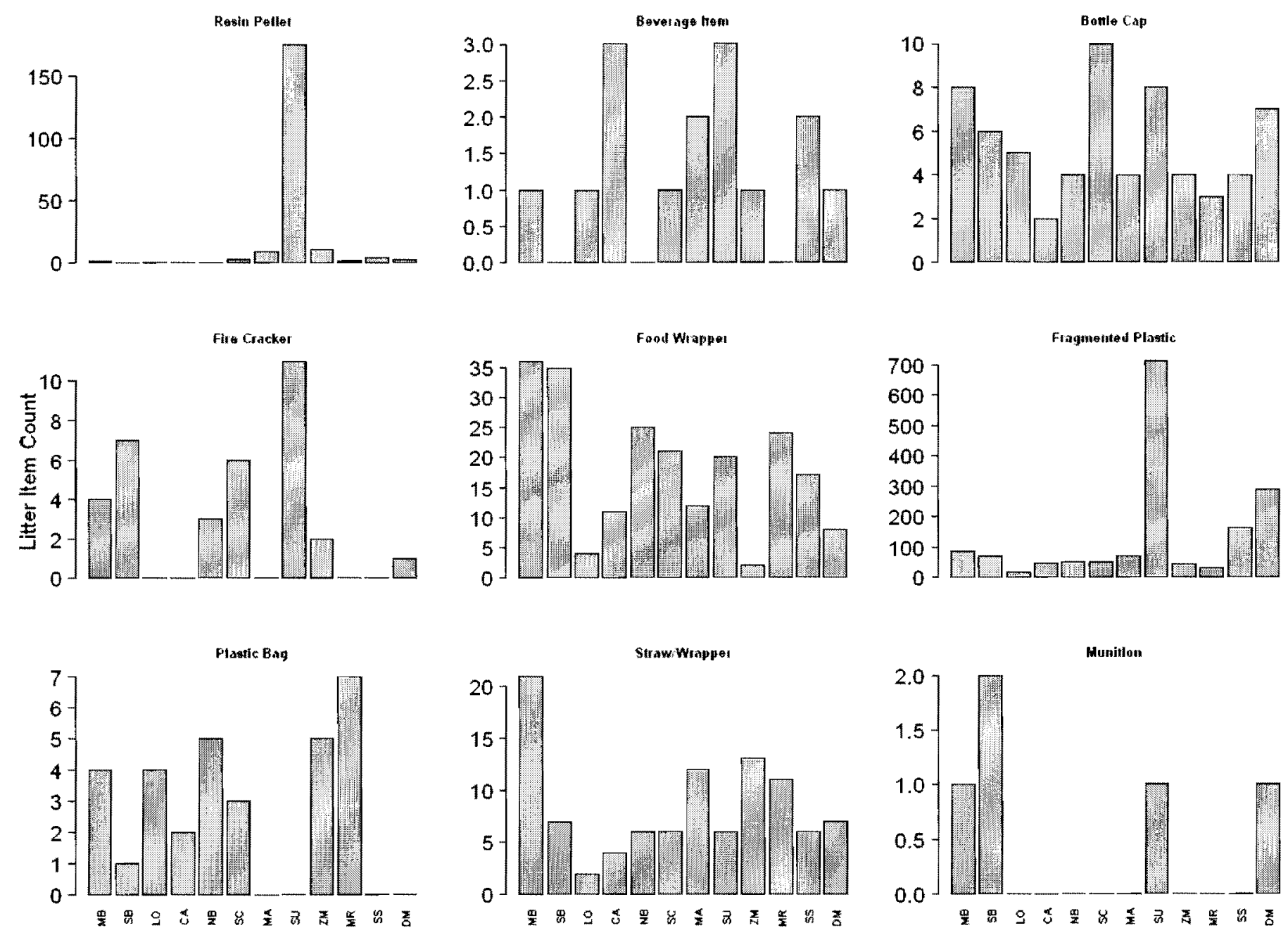

Figure 14. The item count of plastic litter categories across beach locations. 

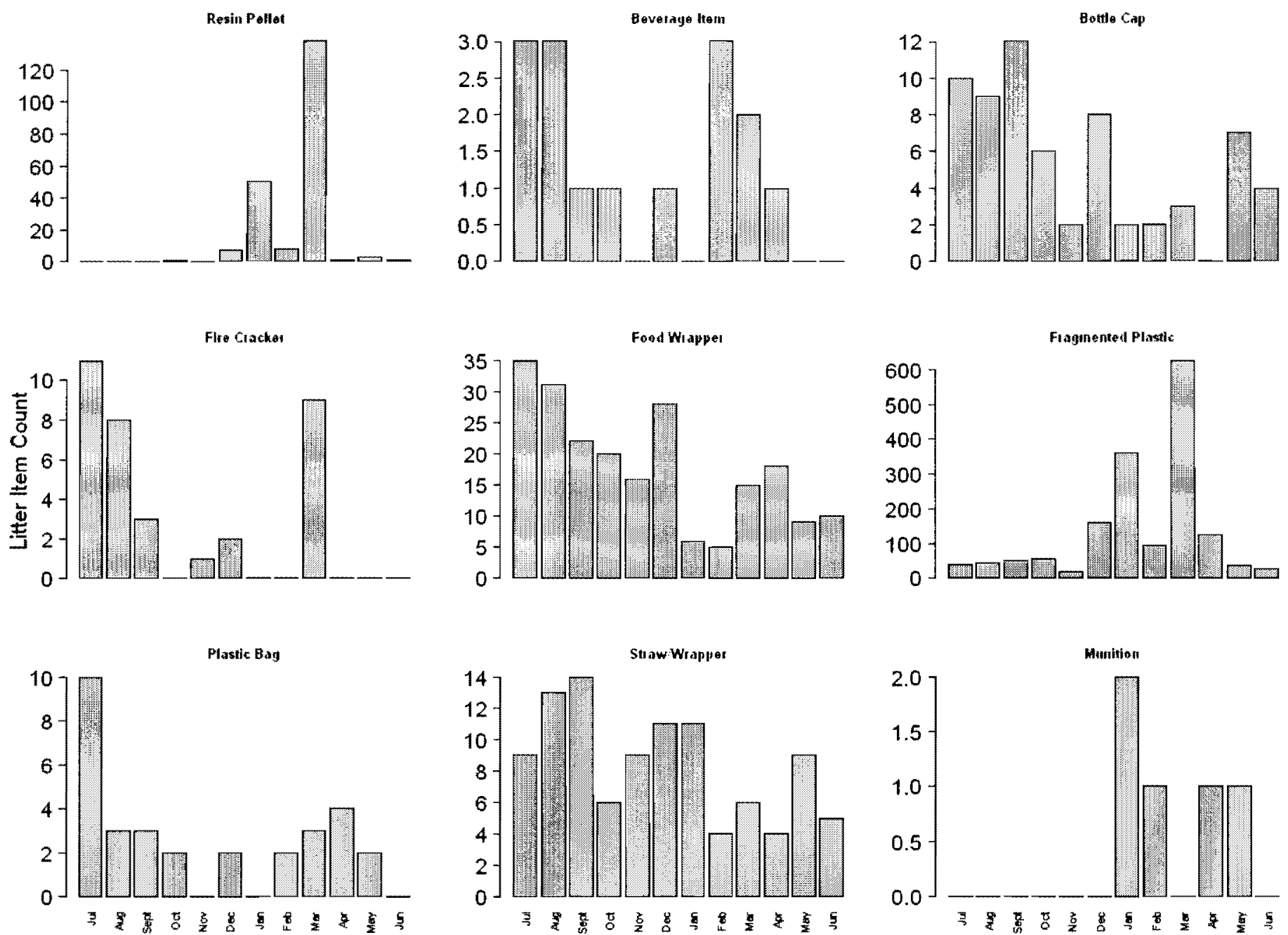

Figure 15. The item count of plastic litter categories across survey months. 


\section{Appendix D}

\section{R-Code}

\#\# Bring abundance data into $\mathrm{R}$ via tinn-R editor.

litter <- read.csv(file.choose())

litter

head ( 1 itter)

str(litter)

summary (Iitter)

\#\# Turn Month and Beach into a factors then assign levels \#to give rise to correct ordering of categorical variables, \# (example) month <- factor(month, levels = c("January", \#"Eebruary", ...., "June").

Iitter\$fMonth<factor (Iitter\$Month, levels=c ( Jul ", "Aug", "Sep t", "Oct", "Nov", "Dec", "Jan", "Feb", "Mar", "Apr", "May", "Jun" )) litter\$fMonth

litter\$fLocation<-factor(litter\$Location, levels= $C$ ("MB", "SB", "LO", "CA", "NB", "SC", "MA", "SU", "ZM", "MR", "SS", "DM"))

litter\$flocation

\#\# Untransformed transformed Abund data.

plot (Iitter)

$\operatorname{par}(\operatorname{mfrow}=\mathrm{C}(2,1))$

hist (litter\$Abund, main="Histogram of Beach Litter", $\mathrm{xlab}=$ "Litter Abundance /m2", ylab="Frequency of Occurance")

\#\# Log transform data and histogram after log transformed.

litter\$LAbund <- $\log (1$ itter\$Abund)

litter $\$$ LAbund

hist (Iitter\$LAbund, main $="$ Log Transformed Histogram of Beach Litter", $\mathrm{xlab}=$ "Litter Abundance /m2", ylab="Frequency of Occurance")\#normal distribution

\#\# Explore data, boxplot of fMonth vs LAbund.

plot (litter\$fMonth, litter\$LAbund, names= c("Jul", "Aug", "Sept", "Oct", "Nov", "Dec", "Jan", "Feb", "Mar", "Apr", "May", "Jun"), 
$\mathrm{xl} a \mathrm{~b}=$ "Month", $\mathrm{yl} \mathrm{ab}=$ expression ( $\mathrm{Log}($ Abundance) $"$ (items $\left./ \mathrm{m}^{\wedge} 2\right)$ ), cex.lab=1, main="Litter abundance over time", datalitter)

\# Explore data, boxplot of fLocation vs LAbund.

plot (Iitter\$fLocation, litter\$LAbund, names= c("Main", "Seabright", "Liveoak", "Capitola", "NewBrighton", "Se acliff", "Manresa", "Sunset", "Zmudowski", "Marina", "Seaside", "DelMonte"), $\mathrm{xlab}=$ "Beach Location", ylab=expression("Abundance" (items $/ \mathrm{m}^{\wedge} 2$ )), cex.lab $=1$, main="Litter abundance variance across Monterey Bay", data $=1$ itter)

$\operatorname{par}(\mathrm{op})$

\# Plot untransformed data for comparison of Month and \#Beach Location vs Abund.

plot (litter\$fMonth, litter\$Abund, names= c("Jul", "Aug", "Sept", "Oct", "Nov", "Dec", "Jan", "Feb", "Mar", "Apr", "May", "Jun") , xlab="Month", ylab=expression("Abundance" (items $\left./ \mathrm{m}^{\wedge} 2\right)$ ), cex.lab=1, main="Litter abundance variance over time", data=litter)

plot (litter\$fLocation, litter\$Abund,

$\mathrm{xlab}=$ "Beach Location", $\mathrm{ylab}=$ expression("Abundance" (items $/ \mathrm{m}^{\wedge} 2$ )), cex.lab $=1$, main="Litter abundance variance across Monterey Bay", data=litter)

\#\# Ready to create models, load appropriate packages.

library (nlme)

library (lattice)

library (stats)

\# Linear regression, simplest models.

M.Imonull <-Im(LAbund $\sim 1$, data =litter)\# No change in litter abundance

M.Imo <- Im(LAbund fMonth + fLocation, data = litter) \# lowest AIC (Model 1)

M.Im1 <- Im(LAbund EMonth, data = litter) \# 2nd lowest AIC. (Model 2)

M.Im2 <- Im(LAbund fLocation, data = litter) \# (Model 3) 
AIC (M. Imonull, M. Imo, M.ImI, M. Im2)

op $<-\operatorname{par}($ mfrow $=C(2,2))$

plot (M.lmonull, main="Residuals vs. null" )

plot (M.lm1, main="Residuals vs. Fitted for Month")

plot (M.Imo, main="Res. vs. Fit for Month and Location")

\#\#\# AIC, Table 1, for publishable table.

AICpilot<-AIC (M.Im0null,M.Im0, M.Im1, M.lm2)

AICpilot

AICtable <- function(aic) \{

$\mathrm{K}<-$ aic $\$ \mathrm{df}$

$\mathrm{n}<-$ length (aic)

$\mathrm{AICC}<-\operatorname{aic} \$ A I C+2 * K *(\mathrm{~K}+1) /(\mathrm{n}-\mathrm{K}-1)$

delAIC <- AICC - min ( AICC)

$A I C w<-\exp (-0.5 * \operatorname{del} A I C) / \operatorname{sum}(\exp (-0.5 * \operatorname{del} A I C))$

\#This is the AIC table to be published:

data.frame( aic, $A I C C$, delAIC, $A I C w)$ \}

AICtable (AICpilot)

\#\#CH 4 Zurr et al.2009,fixed factors, dealing with \#heterogeneity.

M.glsnull <- gls(LAbund $\sim 1$, na.action = na.omit, data $=$ litter)

M.gls0 <- gls(Abund fLocation + fMonth, na.action = na.omit, data $=$ litter)

summary (M.glso); plot (M.glso)

vf2 <- varIdent (form $=\sim 1 \mid$ fMonth) \# good direction.

M.gls1 <- gls(LAbund fLocation + fMonth, na.action = na.omit, weights $=$ vf2, data =litter)

summary (M.gls 1 )

AIC (M.glsnull, M.gls0,M.glsl)

\#\#\#\#\#AIC Table, results of gls using variance structures.

AICpilot<-AIC (M.glsnull, M.glso, M.glsl)

AICpilot

AICtable <- function(aic) \{

$\mathrm{K}<-$ aic $\$ \mathrm{df}$

$\mathrm{n}<-$ length (aic)

AICC <- aic\$AIC + $2 * K *(K+1) /(n-K-1)$

delAIC <- AICC - $\min (A I C C)$

$A I C w<-\exp \left(-0.5^{*} \operatorname{delAIC}\right) / \operatorname{sum}\left(\exp \left(-0.5^{\star} \operatorname{del} \mathrm{AIC}\right)\right)$ 
\#This is the AIC table to be published:

data.frame ( aic, AICC, delAIC, AICW)

AICtable (AICpilot)

\#\#CH 5,Zurr et al. 2009 p.107 Linear Mixed effects \#models (where flocation is random effect).

\#\# The Random Intercept Model.

M.Ime1 <- Ime (LAbund EMonth, random = - I flocation, na. action = na.omit, data $=$ litter $)$ (Model 5)

summary (M.Ime1)

$\operatorname{par}(\operatorname{mfrow}=\mathrm{c}(2,2))$

plot (M.Ime1)

\#\# Same model as above (M.Ime1) includes varIdent.

M.Ime2 <- Ime(LAbund fMonth, random $=\sim 1 \mid$ flocation, weights $=$ vf2, na.action = na.omit, data = litter) \#(Model 6)

plot (M.Ime2)

\# The Random Effects Model.

M.Ime $3<-$ Ime (LAbund 1, random $=\sim 1 \mid$ flocation, weights = vf2, na.action = na.omit, data = litter) \# Lowest $A I C$ summary(Mlme3) \# (Model 7) Did not use in AIC model comparison.

AIC (M.gls0, M.gls2, M.lme1, M.lme2)

\#\#\#\#\# AIC Table 2, results of random and fixed effects models.

AICpilot<-AIC (M.glsnull, M.gls2, M.Ime1, M.Ime2)

AICpilot

AICtable <- function(aic) \{

$\mathrm{K}<-$ aic $\$ \mathrm{df}$

$n<-$ length (aic)

AICC $<-\operatorname{aic\$ AIC}+2 * K *(K+1) /(\mathrm{n}-\mathrm{K}-1)$

$\operatorname{deIAIC}<-A I C C-\min (\mathrm{AICC})$

$A I C w<-\exp (-0.5 * \operatorname{delAIC}) / \operatorname{sum}(\exp (-0.5 * \operatorname{del} A I C))$

\#This is the AIC table to be published:

data.frame ( aic, AICC, delAIC, AICW)

AICtable (AICpilot) 
\#\#\#Independence violations...exploring temporal dependence.

\# May be violating independence, so plot residuals...

$\mathrm{E}<-$ residuals(M.gls2, type = "normalized") \# also included M.gls2 in diagnostics

I1 <- ! is.na (litter\$LAbund)

Efull <- vector (length = length(litter\$LAbund)

Efull[I1] $<-E$

acf(Efull, na.action =na.pass, main="Auto-correlation plot for Model 5 residuals")

\#\# looks like some autocorrelation.

\#\# Testing with "compound symetry autocorrelation \#structure", using GLS model

M.Indep1 <- gls(LAbund $\sim$ fLocation + fMonth, weights = vf2, correlation $=$ corCompsymm (form $=\sim$ fMonth), na.action=na.omit, data = litter

summary (M. Indep1)

\#\#\# ( CorAR1 Can Only Be Integers) Can not use M.Indep2.

M. Indep2 <- gls (LAbund fLocation + fMonth, weights = vf2, correlation $=$ corARl (form $=\sim$ fMonth), na.action=na.omit, data $=$ litter)

\#Error in Initialize.corARI(X[[1L]], ...) :

\#Covariate must have unique values within groups for corAR1 objects

\# Implementing ARMA ( $p, q)$

Cs1 <- CorARMA $(\mathrm{c}(0.2), \mathrm{p}=1, \mathrm{q}=0) \# \mathrm{p}=$ temporal time steps $1-3 ., q=$ noise at previous steps

cs2 <- CorARMA $(c(0.3,-0.3), p=2, q=0)$ \# two time step, zero distance between noise.

Cs $3<-\operatorname{CorARMA}(\mathrm{c}(0.2), \mathrm{p}=0, \mathrm{q}=1)$

Cs $4<-\operatorname{corARMA}(\mathrm{c}(0.3,-0.3), \mathrm{p}=1, \mathrm{q}=1)$

\# Finding optimal model.

M3armal <- gls (LAbund fLocation + fMonth, , weights = vf2, na.action=na. omit,

correlation $=$ Cs1, data $=$ litter $)$ \#AIC $=454.2139, \mathrm{w} / \mathrm{vf2}$ $\mathrm{aic}=444.5088$

summary (M3arma1) 
M3arma2 <- gls(LAbund fLocation + EMonth, , weights = vf2, na.action=na.omit, correlation = cs2, data = litter $\quad \# A I C=454.4873, \mathrm{w} / \mathrm{vf2}$ aic $=445.9504$

M3arma 3 <- gls(LAbund fLocation + fMonth, , weights = vf2, na.action=na.omit, correlation = cs4, data = litter

M3arma4 <- gls (LAbund fLocation + fMonth, , weights = vf2, na.action=na.omit, correlation = cs5, data $=$ litter

AIC (M3arma1, M3arma2, M3arma3, M3arma4)

\# df AIC

\#M3arma1 $26 \quad 444.5088$

\#M3arma2 27445.9504 \#best fit!

\#M3arma3 $26 \quad 444.6528$

\#M3arma4 $27 \quad 446.149$

\#\#\#\#\# Seasonal distribution per survey site.

seasonal . beach<-

matrix $(c(1.475,4.125,2.800,2.025,1.550,1.800,4.500,8.075$, $0.425,0.825,0.550,0.600,1.425,1.175,1.275,0.525,2.825,0.975$ $, 1.450,0.500,1.900,1.175,7.075,0.350,1.500,2.425,2.775,0.30$ $0,0.625,1.750,10.575,17.525,0.875,0.650,21.775,1.600,1.225$, $1.000,1.975,5.025,1.000,0.975,6.725,1.950,1.800,0.750,9.025$ $, 3.500)$, nrow $=12$, byrow $=\mathrm{T}$ )

seasonal.beach

\# Adding rows and column names to a matrix. colnames (seasonal beach) <c("Summer", "Fall ", "Winter", "Spring")

rownames (seasonal . beach) <c ("Main", "SeaBright", "LiveOak" , "Capitola", "NewBrighton", "Se aCliff", "Manresa", "Sunset", "Zmudowski", "Marina", "Seaside", " DelMonte")

seasonal.beach

\# Name the row and column names.

names (dimnames (seasonal.beach)) <- c("Beach

Location", "Season")

seasonal.beach

\# Plot barchart 
$\operatorname{par}(\operatorname{ma} i=c(1,1, .5, .1))$

barplot(as.matrix (seasonal.beach), ylab= expression("Average Abundance" (items $\left./ \mathrm{m}^{\wedge} 2\right)$ ), $x l a b=" S e a s o n ", b e s i d e=T R U E$, cex.lab $=1.5$, cex. axis=1.5, ylim=c $(0,25)$, border="black", $\mathrm{col}=$ topo. colors $(12)$ )

\# Place the legend at the top-left corner with no frame \# using topo colors

legend("topleft", c "Main", "SeaBright", "Liveoak", "Capitola", "NewBrighton", "SeaCliff", "Manresa", "Sunset", "Zmudowski" , "Ma rina", "Seaside", "DelMonte" ), cex=1.5, bt $y=$ "n", border="black", fill=topo. colors (12));

\# XY plots plots Figure 9 and 10 (appendix B)

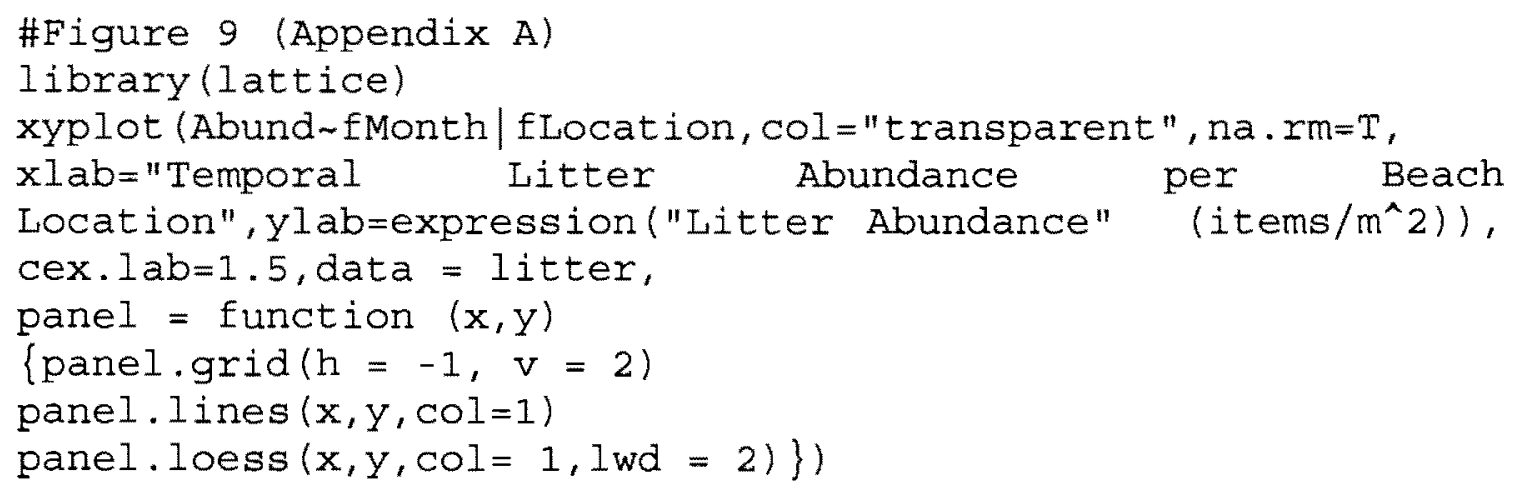

\#Figure 10 (Appendix A)

xyplot (Abund fLocation|fMonth, na.rm=T, xlab="Monthly Litter Abundance across Beach Location", ylab=expression("Litter Abundance" $\left(\right.$ items $\left.\left./ \mathrm{m}^{\wedge} 2\right)\right)$, cex.lab=1.5, data = litter, panel = function $(\mathrm{x}, \mathrm{y})$

\{panel.grid $(\mathrm{h}=-1, \mathrm{v}=2)$

panel points $(x, y, \operatorname{col}=1)$

panel. loess $(x, y, \operatorname{col}=1,1 w d=2)$

\#Figure 12 and 13 (Appendix C)

\# call out each row to make an array of bargraphs per item.

library (base)

$\operatorname{par}(\operatorname{mfrow}=\mathrm{c}(3,4), \operatorname{mai}=\mathrm{c}(0.5,0.7,0.5,0.1))$ 
$\operatorname{par}(\operatorname{mfrow}=\mathrm{c}(1,1))$

barplot (categ. month $[1$,$] , main="Metal", cex. main=2, cex. axis=2,$ las=2, $x a x t=' n ')$

barplot (categ. month [2,], main= "CigaretteButt", cex.main=2, cex . axis=2, las=2, $\operatorname{xaxt}=$ 'n')

barplot (categ. month $[3$,$] , main="Fabric", cex. main=2, cex. axis=2$ , $x a x t=' n ', l a s=2)$

barplot (categ.month [4,], main="FertilizerPellet", cex.main=2, cex. axis=2, xaxt='n', las=2)

barplot (categ.month [5,] , main="FishingGear", cex.main=2, cex.a $x i s=2$, cex. $1 a b=2$, $x a x t=' n^{\prime}, l a s=2, y l a b=$ "Litter Item count") barplot (categ.month [6,], main="FoodWrapper", cex.main=2, cex.a. $x i s=2, \quad x a x t=' n ', l a s=2)$

barplot (categ.month $[7$,$] , main= "FragmentedPlastic", cex. main=2$ , cex.axis=2, las=2, $x a x t=' n '$ ')

barplot (categ. month $[8$,$] , main="Glass", cex. main=2, cex. axis=2,$ las $=2$, $x a x t=' n ')$

barplot (categ.month [9,], main="other") \#\#\#exclude this category for temporal graphic

barplot (categ. month $[10$,$] , main= "Paper/Wood", cex.main=2,$ cex.axis=2, las $=2$ )

barplot (categ.month [11,], main="PlasticProduct", cex.main=2, cex.axis=2, las $=2$ )

barplot (categ.month [12,], main= "Polystyrene" , cex.main=2, cex. axis=2, las $=2$ )

barplot (categ. month $[13$,$] , main="Rubber", cex. main=2, cex. axis=$ $2, \quad$ las $=2$ )

\#Figure 13 (Appendix C)

help (barplot)

$\operatorname{par}(\operatorname{mfrow}=\mathrm{c}(3,4), \operatorname{mai}=\mathrm{c}(0.5,0.7,0.5,0.1))$

barplot (categ.beach $[1$,$] , main="Metal", cex. main=2, cex. axis=2,$ xaxt $=$ 'n', las $=2)$

barplot (categ.beach $[2$,$] , main="CigaretteButt", cex. main=2, cex$ .axis $=2$, xaxt $=$ 'n', las=2)

barplot (categ. beach [3,], main="Fabric", cex. main=2, cex. axis=2 , $x a x t=' n ', 1$ as $=2$ )

barplot (categ.beach [4,], main="FertilizerPellet", cex.main=2, cex. axis=2, xaxt='n', las=2)

barplot (categ.beach $[5$,$] , main="Fishing$

Gear", cex.main=2, cex. axis $=2$, $x a x t=$ ' n', $1 \mathrm{as}=2$, cex. $1 \mathrm{ab}=2$, y $l a b=$ " Litter Item Count")

barplot (categ. beach [6,], main= "FoodWrapper", cex. main=2, cex.a $x i s=2, x a x t=' n ', l a s=2$ ) 
barplot (categ.beach $[7$,$] , main= "FragmentedPlastic", cex.main=2$ , cex.axis=2, $x a x t=' n ', l a s=2)$

barplot (categ.beach $[8$,$] , main="Glass", cex.main=2, cex.axis=2$ , $x a x t=' n ', l$ as $=2$ )

barplot (categ.beach [9,], main="other") \#\#\# exclude this category for temporal graphic

barplot (categ. beach $[10$,$] , main= "Paper /$ wood" , cex. $\operatorname{ma} i n=2$, cex.a $\mathrm{xis}=2, \mathrm{las}=2$ )

barplot (categ.beach $[11$,$] , main="PlasticProduct", cex.main=2, c$ ex.axis=2, las $=2$, cex. $1 a b=2$ )

barplot (categ.beach [12,], main="Polystyrene", cex.main=2, cex. axis $=2,1$ as $=2$ )

barplot (categ. beach $[13$,$] , main="Rubber", cex.main=2, cex. axis=$ $2,1 a s=2$ )

\# Figure 14 and 15 (Appendix C)

\# call out each row to make an array of bargraphs per item.

$\operatorname{par}(\operatorname{mfrow}=\mathrm{C}(3,3), \operatorname{mai}=\mathrm{c}(0.5,0.7,0.5,0.1))$

par (mfrow $=\mathrm{c}(1,1))$

barplot (Plast. beach $[1$,$] , main="ResinPellet", cex.lab=2, cex.ax$ is $=2, \quad x a x t=' n ', l a s=2)$

barplot (Plast. beach $[2$,$] , main="BeverageItem" , cex. 1 \mathrm{ab}=2$, cex.a $\mathrm{xis}=2$, $\mathrm{xaxt}=\mathrm{\prime n}^{\prime}, \mathrm{las}=2$ )

barplot (Plast.beach [3,], main="BottleCap", cex.lab=2, cex.axis $=2, \operatorname{xaxt}=$ 'n', las $=2$ )

barplot (Plast . beach [4,], main="FireCracker" , cex. lab=2, cex. ax is $=2, l a s=2$, xaxt $=$ 'n', ylab="Litter Item count")

barplot (Plast . beach $[5$,$] , main= "FoodWrapper" , cex. lab=2, cex. ax$ is $=2, \quad x a x t=' n ', l a s=2)$

barplot (Plast . beach [6,], main="FragmentedPlastic", cex. $1 \mathrm{ab}=2$, cex. axis=2, xaxt =' n', las =2)

barplot (Plast.beach $[7]$, main= "Misc. ", cex.lab=2, cex.axis=2, $x a x t=' n ') \#$ do not include in graphic

barplot (Plast. beach [8,] , main="PlasticBag", cex. $1 \mathrm{ab}=2$, cex.axi $s=2,1 \mathrm{as}=2)$

barplot (Plast . beach [9, ], main="Straw/Wrapper", cex. lab=2, cex. axis=2, las $=2$ )

barplot (Plast.beach [10,], main="Munition", cex. $1 \mathrm{ab}=2$, cex. axis $=2$, las $=2$ )

\#\# Figure 15 (Appendix C)

$\operatorname{par}(\operatorname{mfrow}=\mathrm{c}(3,3), \operatorname{mai}=\mathrm{c}(0.5,0.7,0.5,0.1))$

par $(\operatorname{mfrow}=\mathrm{C}(1,1))$ 
barplot (Plast.month [1,], main="ResinPellet", cex. lab=2, cex.ax is $=2, \quad x a x t=' n ', l a s=2$ )

barplot (Plast. month [2,], main= "BeverageItem", cex. lab=2, cex.a xis=2, $x a x t=' n ', l a s=2)$

barplot (Plast. month [3,], main="BottleCap", cex. lab=2, cex. axis $=2, \quad x a x t=' n ', l a s=2$ )

barplot (Plast.month [4,], main= "FireCracker", cex. lab=2, cex. ax is $=2$, $x a x t=' n ', l a s=2, y l a b=$ "Litter Item Count")

barplot (Plast.month [5, ], main="FoodWrapper", cex. lab=2, cex. ax is $=2, \quad x a x t=' n ', l a s=2$ )

barplot (Plast. month $[6$,$] , main= "FragmentedPlastic", cex. 1 \mathrm{ab}=2$, cex. axis=2, xaxt='n', las $=2$ )

barplot(Plast.month[7,], main= "Misc.", xaxt='n')\# do not include in graphic

barplot (Plast.month [8, ], main="PlasticBag", cex. lab=2, cex.axi $s=2,1$ as $=2$ )

barplot (Plast. month [9,], main="Straw/Wrapper", cex. 1 ab=2, cex. axis $=2,1$ as $=2$ )

barplot (Plast. month [10,] , main="Munition", cex. lab=2, cex.axis $=2$, las $=2$ ) 